\title{
Hydrocarbon-like and oxygenated organic aerosols in Pittsburgh: insights into sources and processes of organic aerosols
}

\author{
Q. Zhang ${ }^{1, *}$, D. R. Worsnop ${ }^{2}$, M. R. Canagaratna ${ }^{2}$, and J. L. Jimenez ${ }^{1,3}$ \\ ${ }^{1}$ Cooperative Institute for Research in Environmental Sciences (CIRES), 216 UCB, University of Colorado-Boulder, Boulder, \\ Colorado 80309-0216, USA \\ ${ }^{2}$ Aerodyne Research Inc., Billerica, Massachusetts 01821-3976, USA \\ ${ }^{3}$ Department of Chemistry and Biochemistry, 216 UCB, University of Colorado-Boulder, Boulder, Colorado 80309-0216, \\ USA \\ * now at: Atmospheric Science Research Center, State University of New York, 251 Fuller Rd, Albany, NY 12204, USA
}

Received: 8 August 2005 - Published in Atmos. Chem. Phys. Discuss.: 9 September 2005

Revised: 7 December 2005 - Accepted: 7 December 2005 - Published: 14 December 2005

\begin{abstract}
A recently developed algorithm (Zhang et al., 2005) has been applied to deconvolve the mass spectra of organic aerosols acquired with the Aerosol Mass Spectrometer (AMS) in Pittsburgh during September 2002. The results are used here to characterize the mass concentrations, size distributions, and mass spectra of hydrocarbon-like and oxygenated organic aerosol (HOA and OOA, respectively). HOA accounts for $34 \%$ of the measured organic aerosol mass and OOA accounts for $66 \%$. The mass concentrations of HOA demonstrate a prominent diurnal profile that peaks in the morning during the rush hour and decreases with the rise of the boundary layer. The diurnal profile of OOA is relatively flat and resembles those of $\mathrm{SO}_{4}^{2-}$ and $\mathrm{NH}_{4}^{+}$. The size distribution of HOA shows a distinct ultrafine mode that is commonly associated with fresh emissions while OOA is generally concentrated in the accumulation mode and appears to be mostly internally mixed with the inorganic ions, such as $\mathrm{SO}_{4}^{2-}$ and $\mathrm{NH}_{4}^{+}$. These observations suggest that HOA is likely primary aerosol from local, combustion-related emissions and that OOA is secondary organic aerosol (SOA) influenced by regional contributions. There is strong evidence of the direct correspondence of OOA to SOA during an intense new particle formation and growth event, when condensational growth of OOA was observed. The fact that the OOA mass spectrum from this event is very similar to that from the entire study suggests that the majority of OOA in Pittsburgh is likely SOA. $\mathrm{O}_{3}$ appears to be a poor indicator for OOA concentration while $\mathrm{SO}_{4}^{2-}$ is a relatively good surrogate for this dataset. Since the diurnal averages of HOA track those of $\mathrm{CO}$ during day time, oxidation/aging of HOA appears to be very small on the time scale
\end{abstract}

Correspondence to: J. L. Jimenez

(jose.jimenez@colorado.edu) of several hours. Based on extracted mass spectra and the likely elemental compositions of major $m / z$ 's, the organic mass to organic carbon ratios (OM:OC) of HOA and OOA are estimated at 1.2 and $2.2 \mu \mathrm{g} / \mu \mathrm{gC}$, respectively, leading to an average OM:OC ratio of 1.8 for submicron OA in Pittsburgh during September. The C:O ratio of OOA is estimated at 1:0.8. The carbon contents in HOA and OOA estimated accordingly correlate well to primary and secondary organic carbon, respectively, estimated by the OC/EC tracer technique (assuming POC-to-EC ratio=1). In addition, the total carbon concentrations estimated from the AMS data agree well with those measured by the Sunset Laboratory Carbon analyzer $\left(r^{2}=0.87\right.$; slope $\left.=1.01 \pm 0.11\right)$. Our results represent the first direct estimate of the OM:OC ratio from highly timeresolved chemical composition measurements.

\section{Introduction}

Organic compounds are ubiquitous and abundant in ambient aerosols. They typically account for $20-50 \%$ of the fine particle mass (Jacobson et al., 2000; Kanakidou et al., 2005; NARSTO, 2003; Saxena and Hildemann, 1996; Seinfeld and Pankow, 2003) and are often internally mixed in the same particles with inorganic aerosols (Middlebrook et al., 2003, 1998; Murphy et al., 1998). Organic compounds play important roles in the formation, growth, and removal of ambient aerosols (IPCC, 2001). They also significantly affect the hygroscopicity (Saxena et al., 1995), toxicity (Sheesley et al., 2005), direct radiative properties (Chung and Seinfeld, 2002; Haywood and Boucher, 2000), and indirect effects (Facchini et al., 1999) of atmospheric aerosols and therefore have major implications for climate, visibility, and human health.

(C) 2005 Author(s). This work is licensed under a Creative Commons License. 
Elucidating the urban-to-global roles as well as the sources and fate of atmospheric aerosols inherently must rely on a thorough understanding of the chemical and microphysical properties of particulate organics. However, it is extremely difficult to obtain a complete description of the molecular composition of aerosol organics because of the number, complexity, and extreme range of physical and chemical properties of these compounds. Usually analysis of over a hundred different molecules can only account for $10-20 \%$ of the organic mass (NARSTO, 2003; Rogge et al., 1993). For these reasons in order to understand the chemistry of atmospheric organic aerosols, bulk characterization approaches such as those targeting compound classes and/or bulk properties (Fuzzi et al., 2001; Gelencser, 2004; Murphy, 2005) should be developed in addition to compound-specific techniques.

Spectroscopic techniques, including Fourier transform infrared (FTIR) spectroscopy (Allen et al., 1994; Blando et al., 1998, 2001; Edney et al., 2003; Laurent and Allen, 2004; Maria et al., 2002; Russell, 2003) and nuclear magnetic resonance (NMR) (Decesari et al., 2005, 2000; Fuzzi et al., 2001), have been applied to characterize the functional group composition of aerosol organics. A major advantage of these techniques is that they characterize ambient aerosols based on the majority of the organic mass, rather than a limited number of molecules (Allen et al., 1994; Blando et al., 1998; Decesari et al., 2000; Fuzzi et al., 2001; Maria et al., 2002). However, in analysis of ambient samples, both FTIR and NMR methods rely on assumptions about the relationship between the strength of the electromagnetic interaction and the amount of material that may introduce significant uncertainties in quantification of functional groups (Blando et al., 2001; Fuzzi et al., 2001). In addition, until now neither method has been adapted for real-time sampling, nor are they capable to determine ambient organic aerosols with high time and size resolution.

Mass spectrometry techniques have been widely used in aerosol analysis because of their universal, extremely sensitive, and rapid detection of aerosol components (Jayne et al., 2000; Jimenez, 2005; Johnston, 2000; McKeown et al., 1991; Murphy, 2005; Noble and Prather, 2000; Suess and Prather, 1999). Among these, the Aerodyne Aerosol Mass Spectrometer (AMS) (Jayne et al., 2000; Jimenez et al., 2003) is the most commonly used. It is capable of quantitatively measuring the size-resolved mass concentrations of organic aerosols with a time resolution of minutes (e.g., Allan et al., 2003a; Drewnick et al., 2004a, b; Jimenez et al., 2003; Zhang et al., 2005b). Good correlations between the mass concentrations of organic aerosols measured by an AMS and the organic carbon concentrations measured by thermal-optical Carbon Analyzers have been observed in various locations, including Pittsburgh (Zhang et al., 2005b), Houston (Canagaratna et al., 2005 ${ }^{1}$ ), Tokyo (Takegawa et al., 2005b), and the coast

\footnotetext{
${ }^{1}$ Canagaratna, M., Jimenez, J. L., Silva, P., et al.: Time resolved
}

of New England (Bates et al., 2005; de Gouw et al., 2005).

The AMS employs thermal vaporization (usually at $600^{\circ} \mathrm{C}$ ) and $70 \mathrm{eV}$ electron ionization that generally causes extensive fragmentation of organic molecules (Alfarra, 2004; Jayne et al., 2000; Jimenez et al., 2003). As a result, in ambient analysis each mass-to-charge ratio $(\mathrm{m} / \mathrm{z})$ peak in an AMS mass spectrum may contain contributions from many different molecules. For this reason the AMS does not characterize individual molecules in ambient air, but rather the methodology fits into the group of techniques that characterizes bulk chemistry of organic aerosols.

A recently developed custom principal component analysis technique makes it possible to use an AMS to identify and quantify broad aerosol "classes" that have different temporal and mass spectral signatures (Zhang et al., 2005a). When applied in urban areas, this technique deconvolves and quantifies two types of organic aerosols, hydrocarbon-like and oxygenated (HOA and OOA, respectively), which together account for almost all the organic aerosol mass measured by the AMS (Zhang et al., 2005a). Hydrocarbon-like aerosols are named based on the similarity of their AMS mass spectra to those of hydrocarbons mixtures, while oxygenated organic aerosols are named based on their high oxygen content (Zhang et al., 2005a). More importantly, this technique allows the extraction of mass concentrations, size distributions, and mass spectra of HOA and OOA that are physically and chemically meaningful. As reported by Zhang et al. (2005a), the extracted mass spectrum of HOA is remarkably similar to the spectra of directly sampled vehicle exhaust and lab-generated lubricating oil aerosols, while the spectrum of OOA closely resembles those of highly processed organic aerosols sampled at rural and remote locations. The OOA spectrum also shows similarity with that of fulvic acid (Alfarra, 2004; Zhang et al., 2005a) - a humiclike substance that is ubiquitous in the environment and has previously been used as an analogue to represent polyacid components found in highly processed and oxidized atmospheric organic aerosols (Decesari et al., 2002).

In this paper we report the application of this technique to the AMS data acquired at the U.S. EPA Pittsburgh Supersite and the major findings regarding the time trends, concentrations, and size distributions of HOA and OOA in Pittsburgh. These results complement two earlier publications from us that discuss the chemistry of new particle growth (Zhang et al., 2004) and the general characteristics of submicron aerosol species (inorganic ions + organics) in Pittsburgh (Zhang et al., 2005b). Because those two articles were published before the development of the HOA and OOA deconvolution technique (Zhang et al., 2005a) discussions concerning aerosol organics in both were made based on analysis of total organic signals and a few $m / z$ fragments. Only in this current paper are we able to provide an in-depth analysis of

aerosol size and chemical composition measured during the Texas Air Quality Study, in preparation, 2005. 
the possible sources and processes of organic aerosols based on 1) correlations of HOA and OOA with gas phase and organic carbon measurements; 2) temporal variations, size distributions, and mass spectra of HOA and OOA; and 3) the dynamics of HOA and OOA during an intense new particle formation and growth event.

\section{Experimental and data analysis methods}

The AMS data used for this study were acquired during 722 September 2002 from the main site of the Pittsburgh Air Quality Study (PAQS). Dates and times are reported in Eastern Standard Time (EST). The local time during this study was Eastern Daylight Savings Time (EDT), which is $1 \mathrm{~h}$ ahead of EST. An overview on the sampling location, instrumentation, and the objectives of PAQS is given elsewhere (Wittig et al., 2004). Gas-phase and meteorological variables were measured simultaneously (Wittig et al., 2004). Note that the original $\mathrm{CO}$ data of this study period were offset by $-0.35 \mathrm{ppm}$ to adjust the average minimum $\mathrm{CO}$ concentration during periods of very clean air (e.g., air masses from the north) to $\sim 0.1 \mathrm{ppm}$, which is the background concentration of $\mathrm{CO}$ in Northern Hemisphere (Finlayson-Pitts and Pitts, 2000). 2-h averaged $\mathrm{PM}_{2.5}$ EC and OC were measured in situ using a Sunset Laboratory thermal optical transmittance carbon analyzer (sampling details are given by Polidori et al., 2005²).

Detailed information on the AMS operation and data analysis is presented by Zhang et al. (2005b, 2004). The mass concentrations and size distributions of fine particle species (e.g., $\mathrm{SO}_{4}^{2-}, \mathrm{NO}_{3}^{-}, \mathrm{NH}_{4}^{+}$, and organics) measured by the AMS during this study compare well with measurements made by collocated instruments, with some systematic differences due to different size cuts (Zhang et al., 2005b). The absolute accuracy of the data reported here is mainly limited by the uncertainties in AMS particle collection efficiency (Zhang et al., 2005b).

The mass concentrations and mass spectra of HOA and OOA were derived using the deconvolution procedures described in a separate publication (Zhang et al., 2005a). This technique involves a series of multivariate linear regressions that use mass-to-charge ratios $\left(\mathrm{m} / \mathrm{z}^{\prime} \mathrm{s}\right) 57$ (mostly $\left.\mathrm{C}_{4} \mathrm{H}_{9}^{+}\right)$and 44 (mostly $\mathrm{CO}_{2}^{+}$), the identified AMS mass spectral tracers for HOA and OOA, respectively, as the time series of the initial principal components followed by an iterative algorithm to determine HOA and OOA time series and mass spectra. The time resolution of the HOA and OOA time series are 5-10 min.

\footnotetext{
${ }^{2}$ Polidori, A., Turpin, B. J., Lim, H.-J., Cabada, J. C., Subramanian, R., Robinson, A. L., and Pandis, S. N.: Local and regional secondary organic aerosol: Insights from a year of semi-continuous carbon measurements at Pittsburgh, Aerosol Sci. Technol., submitted, 2005.
}

Because of the use of a quadrupole mass spectrometer only a subset of $m / z$ 's (16 in total, out of which 8 are mainly organic $m / z$ 's) were scanned for size distributions in this study (Jayne et al., 2000; Jimenez et al., 2003; Zhang et al., 2005b). We are thus unable to derive the size distributions of HOA and OOA using the full mass spectra. Those presented in this study are derived based on the measured size distributions of $m / z$ 's 57 and 44 because they are the first order AMS tracers for OOA and HOA, respectively, and correlate closely to the HOA and OOA time series (Zhang et al., 2005a). The size distribution of OOA was derived by normalizing the integrated signals of $m / z, 4$ in $20-1500 \mathrm{~nm}$ particles to the estimated concentrations of OOA. Note that this size range was selected to ensure the capture of all particle signals. The first paper on the AMS showed about 50\% transmission at $1000 \mathrm{~nm}$, which is typically referred to as $\mathrm{PM}_{1}$ (Fig. 9 on Jayne et al., 2000) and a detailed analysis of signals from Pittsburgh AMS data showed partial transmission for particles down to $33 \mathrm{~nm}$ (Zhang et al., 2005a). Slightly different aerodynamic lens designs have been used in the AMS, including during this study, and each lens may have slightly different particle transmission characteristics. This is a subject of ongoing research that will be presented in a future publication.

The potential for interferences to $m / z 44$ to cause differences between the real size distribution of OOA and the distribution presented here is low because of the very high correlation of $m / z, 44$ and OOA and the lack of $m / z 44$ signal in the HOA mass spectrum (Zhang et al., 2005a). However, considering that $m / z 57$ is present in the OOA mass spectrum at intensity $\sim 2 \%$ of that of $m / z 44$, which indicates that $m / z 57$ may have contributions from oxygenated species (e.g., $\mathrm{C}_{3} \mathrm{H}_{5} \mathrm{O}^{+}$) in addition to hydrocarbons (i.e., $\mathrm{C}_{4} \mathrm{H}_{9}^{+}$), we derived the size distribution of HOA by subtracting $2 \%$ of the $m / z, 44$ signal from the size distribution of $m / z 57$ and then normalizing the integrated signals in $20-1500 \mathrm{~nm}$ particles to the estimated concentrations of HOA. The presence of oxygenated $m / z 57\left(\mathrm{C}_{3} \mathrm{H}_{5} \mathrm{O}^{+}\right)$when the OOA to HOA ratio is high has been confirmed by recently acquired high $\mathrm{m} / \mathrm{z}$ resolution AMS data.

Organic mass to organic carbon ratios (OM:OC) of HOA and OOA are estimated based on the extracted mass spectra of the two components (Zhang et al., 2005a) and the likely elemental compositions of the major $m / z$ 's in the corresponding spectrum. All the data reduction and analysis are performed with Igor Pro 5 (Wavemetrics Inc.). 

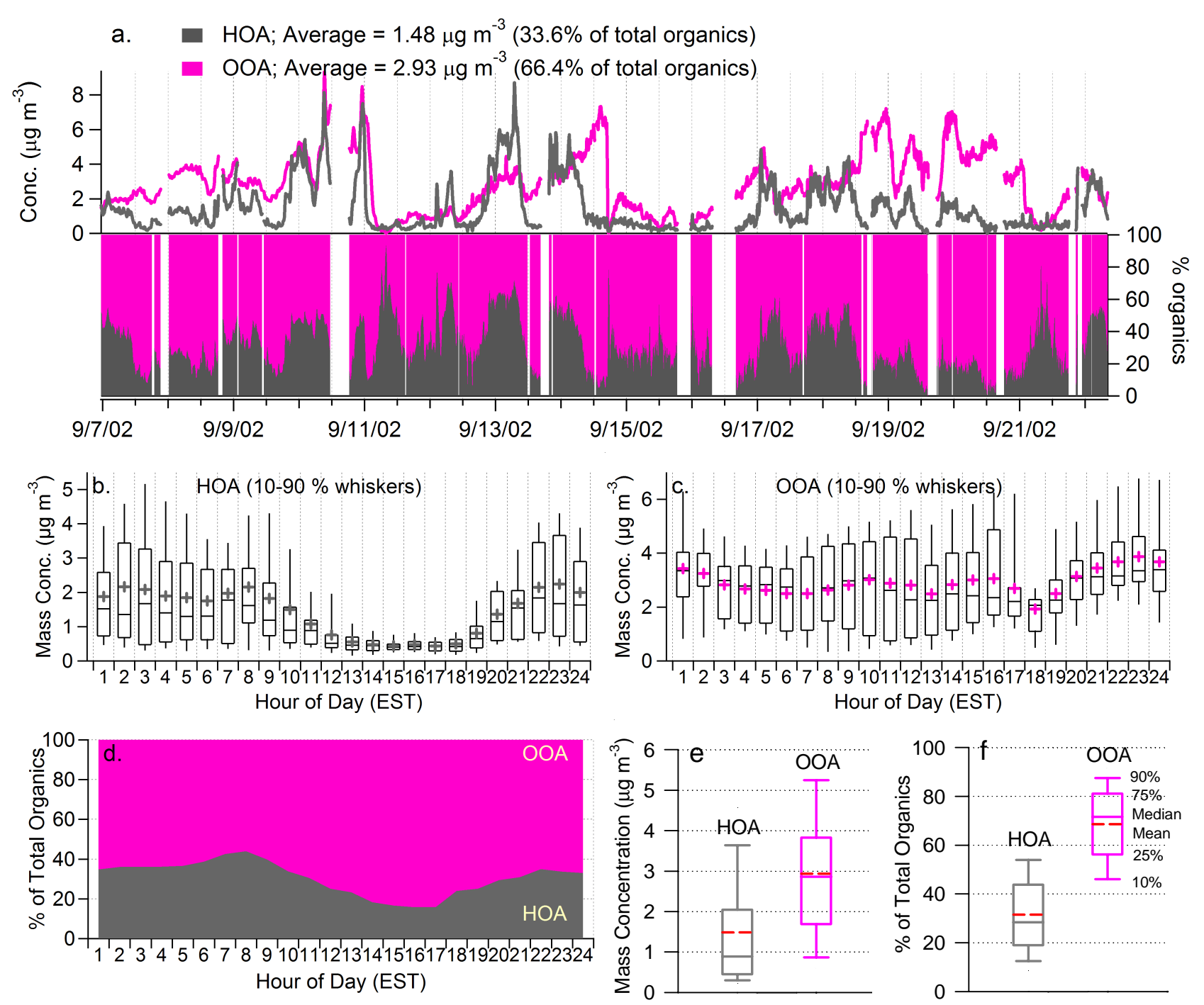

Fig. 1. (a) Time series of the absolute and fractional HOA and OOA in Pittsburgh during 7-22 September 2002. Missing data points are due to either occasional instrumental malfunction or maintenance/calibration. Average diurnal cycles of the mass concentrations of (b) HOA and (c) OOA. (d) Average diurnal cycles of the fractional contribution of HOA and OOA to the total organic aerosol mass. Box plots of (e) the mass concentration and (f) the fractional contribution of HOA and OOA to total organics. The box plots are read as follows: the upper and lower boundaries of the box indicate the 75th and the 25 th percentiles, the solid line within the box marks the median, the whiskers above and below the box indicate the 90th and 10th percentiles. Cross symbols or the red broken lines represent the means. The results of the statistical analysis are given in Table 1. The $\mathrm{x}$-axis labels of the diurnal plots corresponds to the hour that ends the averaging interval and the ordinal of the hour in the day, e.g., "1" means the first hour of the day, from 00:00-01:00 a.m. EST.

\section{Results and discussion}

3.1 Mass concentrations and temporal variations of HOA and OOA

\subsubsection{Mass concentrations and diurnal variations of HOA and OOA}

The time series of the mass concentration and the fractional contribution of hydrocarbon-like and oxygenated organic aerosols are shown in Fig. 1 (and see Zhang et al., 2005a). During this study in Pittsburgh the mass concentrations of atmospheric fine particles changed dramatically. Multiday episodes of fine particle pollution are interleaved with clean periods following heavy rainfall and/or the arrival of clean air from the north. The time trends of HOA and OOA are very different, except for a few periods when their concentrations appear to co-vary due to the arrival of clean air masses and/or rainfall scavenging. In general, the time series of HOA demonstrates a pronounced variation pattern that typically peaks during morning rush hours, when the mixing layer is relatively shallow and primary emissions from traffic 


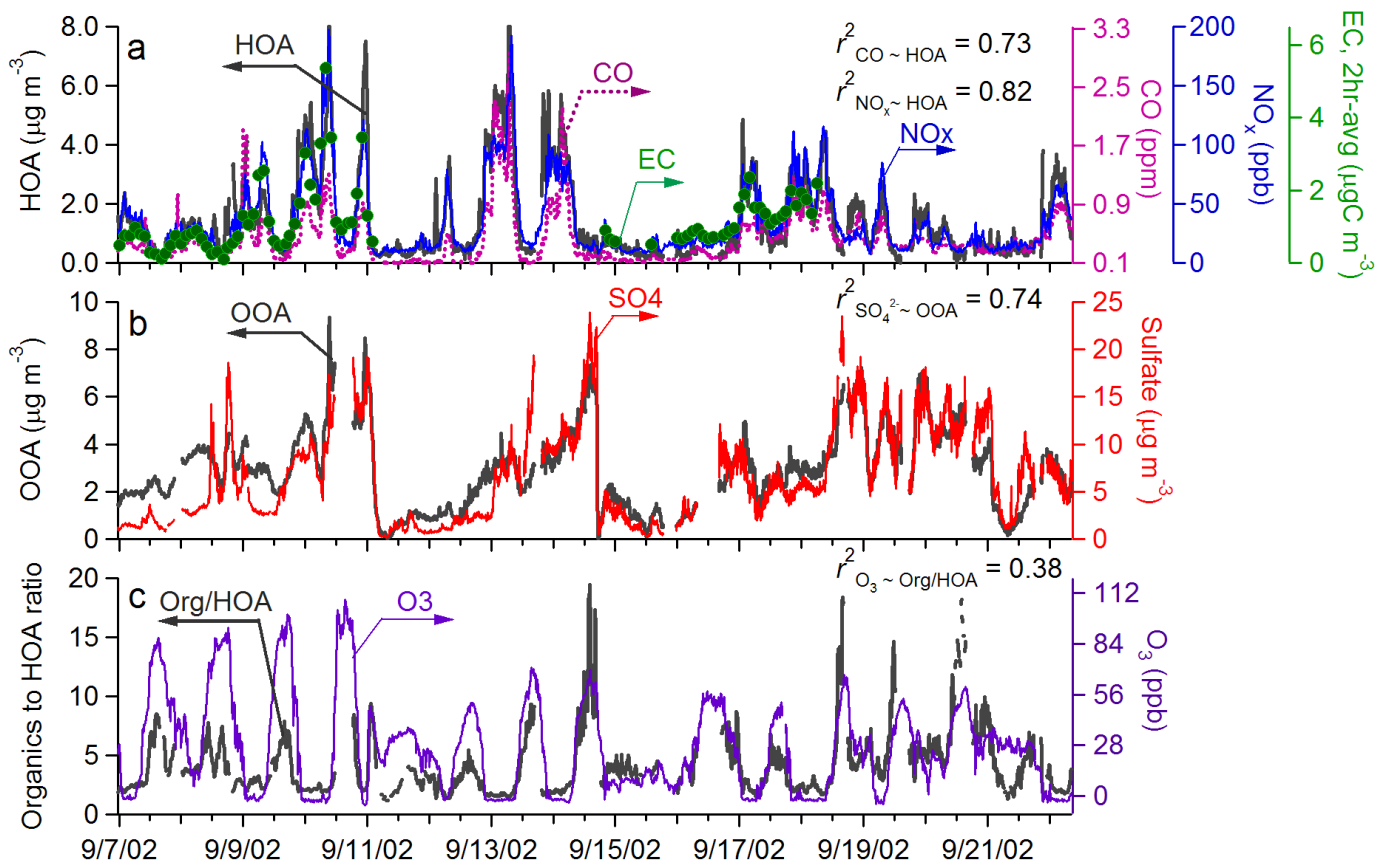

Fig. 2. Time trends of (a) $\mathrm{HOA}$ and typical combustion emission tracers $\left(\mathrm{CO}, \mathrm{NO}_{\mathrm{x}}, \mathrm{EC}\right.$ ), (b) OOA and $\mathrm{PM}_{1} \mathrm{SO}_{4}^{2-}$ (both from the $\mathrm{AMS}$ ), and (c) the OOA to organic mass ratio and $\mathrm{O}_{3}$ during 7-22 September 2002 in Pittsburgh.

are intense. OOA demonstrates a time trend similar to that of sulfate (Fig. 2b), a dominant secondary aerosol species that is strongly influenced by regional accumulation rather than local emissions in Pittsburgh (Zhang et al., 2005b).

The significantly different diurnal patterns of HOA and OOA are evident in Figs. $1 \mathrm{~b}$ and c. Note that these diurnal averages may be skewed by a few abnormally low/high loading events due to the relatively short duration of this study (16 days). The dip at the 18th hour (between 5:00 to 6:00 p.m.) on the diurnal curve of OOA, for example, is mainly caused by the abrupt drop in the mass concentration associated with a rainfall event in the afternoon of 15 September. HOA demonstrates a clear diurnal pattern that peaks in the morning during the rush hour (8:00-9:00 a.m.), gradually decreases after 8:00 a.m., and reaches its minimum between 3:00-5:00 p.m. In contrast, the OOA diurnal profile is relatively flat and resembles those of $\mathrm{SO}_{4}^{2-}$ and $\mathrm{NH}_{4}^{+}$ (Zhang et al., 2005b). In addition, while the trend is relatively weak, the mean values of OOA show slight increases in the afternoon between 13:00 to 16:00 EST (Fig. 1c), when photochemistry is relatively intense. As a result, the highest fraction of OOA was observed in the afternoon around 15:00-17:00 EST, during which OOA accounts for more than $80 \%$ of the total organic mass on average (Fig. 1d).

Table 1 and Figs. 1e, f summarize the statistics of the mass concentrations of HOA and OOA and their fractional contributions to the total organics. OOA dominates organic aerosol mass loading in Pittsburgh, accounting for more than half of the organic mass for $\sim 85 \%$ of the time during this
Table 1. Statistical parameters of the distributions of the mass concentrations of HOA and OOA, and of their fractional contributions to the total organic mass in Pittsburgh during 7-22 September 2002.

\begin{tabular}{ccccc}
\hline & \multicolumn{2}{c}{ Mass Concentration $\left(\mu \mathrm{g} \mathrm{m}^{-3}\right)$} & \multicolumn{2}{c}{ of Total Organics } \\
& HOA & OOA & HOA & OOA \\
\hline Mean & 1.48 & 2.93 & 31 & 69 \\
$1 \sigma$ & 1.44 & 1.65 & 16 & 16 \\
Median & 0.89 & 2.86 & 28 & 72 \\
Min & $<$ D.L. & $<$ D.L. & 0 & 7 \\
Max & 8.71 & 9.33 & 93 & 100 \\
90th percentile & 3.63 & 5.25 & 54 & 88 \\
75th percentile & 2.04 & 3.83 & 44 & 81 \\
25th percentile & 0.45 & 1.69 & 19 & 56 \\
10th percentile & 0.30 & 0.87 & 12 & 46 \\
\hline
\end{tabular}

a These values are obtained by analyzing the relative concentrations (percent values) of HOA and OOA, rather than estimated from the absolute mass concentration statistics.

b D.L.: Detection limit of organic mass concentration, which was estimated to be $0.15 \mu \mathrm{g} \mathrm{m}^{-3}$ for this study (Zhang et al., 2005b).

study (Fig. 1a). The average $( \pm 1 \sigma)$ mass concentration of OOA is $2.93( \pm 1.65) \mu \mathrm{g} \mathrm{m}^{-3}$, roughly twice that of HOA $\left(1.48 \pm 1.44 \mu \mathrm{g} \mathrm{m}^{-3}\right.$; Figs. 1e, f). On average, HOA represents $34 \%$ of the organic aerosol mass in Pittsburgh while OOA accounts for $66 \%$. Even during the morning rush hour, the mass loading of OOA is larger than that of HOA on average (Fig. 1d). 

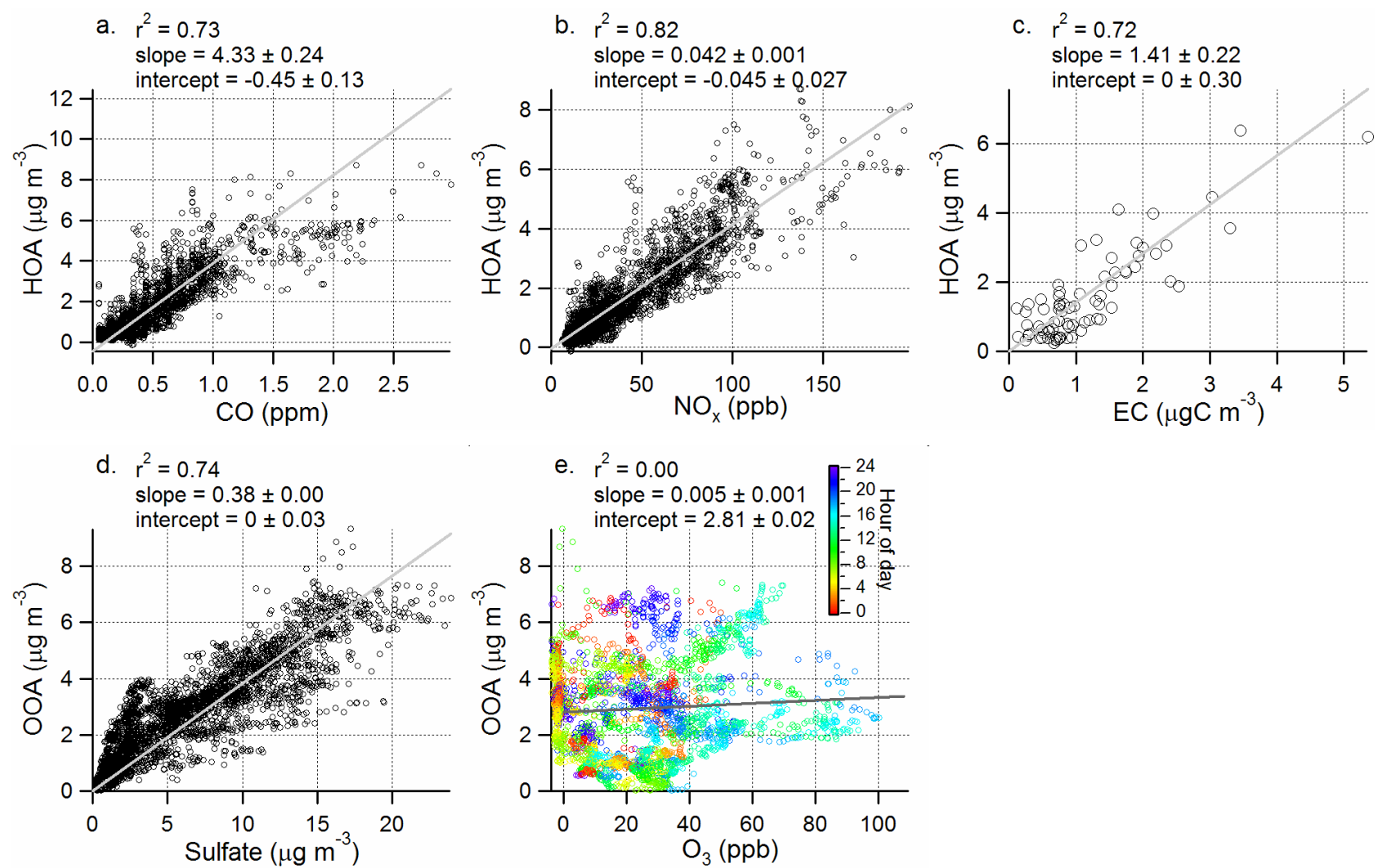

Fig. 3. Scatter plots of the concentrations of (a) HOA vs. CO; (b) HOA vs. $\mathrm{NO}_{\mathrm{x}}$; (c) HOA vs. elemental carbon; (d) OOA vs. sulfate; and (e) $\mathrm{OOA}$ vs. $\mathrm{O}_{3}$ (data points are colored by hour of day).

\subsubsection{Correlation of HOA and OOA with combustion and secondary aerosol tracers}

Figure 2a shows the time series of HOA together with three primary combustion emission tracers - $\mathrm{CO}, \mathrm{NO}_{\mathrm{x}}$, and elemental carbon (EC). Figure $2 b$ shows the time series of OOA and sulfate - a secondary aerosol species that is mainly formed through gas-phase and aqueous-phase oxidation of $\mathrm{SO}_{2}$. The corresponding linear regression scatter plots are shown in Figs. 3a-d.

HOA correlates well with $\mathrm{CO}\left(r^{2}=0.73\right), \mathrm{NO}_{\mathrm{x}}\left(r^{2}=0.82\right)$, and EC $\left(r^{2}=0.72\right)$, all of which demonstrate a pronounced diurnal pattern that peaks in the morning when traffic emissions are intense, declines with the rise of the mixed layer depth, and gradually increases after the boundary layer collapses in the evening. Such diurnal behavior is characteristics for air pollutants from local emissions and thus indicates a strong association of HOA to combustion aerosol emitted locally (e.g., from traffic). This hypothesis is consistent with the size distribution of HOA, which constantly shows a prominent ultrafine mode that is common for combustion aerosols (see Sect. 3.2). The mass spectrum of HOA is also very similar to those of freshly emitted vehicle exhaust aerosols, showing ion series characteristic of hydrocarbons (see Sect. 3.3 and Zhang et al., 2005a).
The time trend of OOA tracks that of $\mathrm{SO}_{4}^{2}\left(r^{2}=0.74\right)$ but correlates very weakly to the combustion tracers $\left(r^{2}<0.1\right)$. The good correlation between OOA and $\mathrm{SO}_{4}^{2-}$ suggests similar sources and/or processes of these two aerosol components. $\mathrm{SO}_{4}^{2-}$ is a major fine particulate species in Pittsburgh due to the high $\mathrm{SO}_{2}$ emissions in this geographical region (Wittig et al., 2004; Zhang et al., 2005b). The atmospheric concentration of $\mathrm{SO}_{4}^{2-}$ is strongly influenced by regional accumulation rather than local production since a significant fraction of the fine particles in Pittsburgh are aged over regional scales (Anderson et al., 2004; Tang et al., 2004). For these reasons the rather weak response of the ambient concentrations of $\mathrm{OOA}$ and $\mathrm{SO}_{4}^{2-}$ to the daily fluctuation of mixed layer depth is indicative of the regional nature of both components (i.e., similar levels of $\mathrm{SO}_{4}^{2-}$ and OOA in the morning boundary layer and in air aloft). This is in contrast to HOA, which originates predominantly from local emissions and as expected demonstrates a pronounced diurnal pattern that peaks in the morning when traffic emissions are high and the mixed layer depth is low.

The lack of strong diurnal variations of $\mathrm{SO}_{4}^{2-}$ and OOA might also be the result of their relatively high background concentrations in the region - daily photochemical production of these two components, which is usually most intense in the afternoon, tends to be dwarfed by the much stronger 
variations in mass concentrations associated with changes of air mass or rainfall scavenging. Note that in areas where fine particles are more strongly influenced by local photochemistry, such as in Mexico City, photochemical production of oxygenated organics is sufficiently pronounced that a clear increasing trend of OOA is often observed during morning and early afternoon ${ }^{3}$. OOA in Pittsburgh appears to be primarily secondary organic aerosol associated with regional accumulation rather than from local emissions. This hypothesis is consistent with the size distributions of OOA, which are dominated by the accumulation mode (see Sect. 3.2), and its mass spectrum, which closely resembles those of aged and highly oxidized organic aerosols (see Sect. 3.2 and Zhang et al., 2005a).

\subsubsection{Correlation of OOA to $\mathrm{O}_{3}$}

A previous study in Pittsburgh reported the use of ozone as an indicator for SOA formation supported by the observation that increases in the OC-to-EC ratio correlate with ozone increases (Cabada et al., 2004a). However, we found very little correlation between $\mathrm{O}_{3}$ and OOA during this study $\left(r^{2} \approx 0\right.$; Fig. 3e), which suggests that ozone concentration is a rather poor indicator for SOA concentration, at least for this study period.

A possible explanation for the positive correlation of SOA to $\mathrm{O}_{3}$ observed by Cabada et al. (2004a) is that the POC/EC ratios used in their EC/OC tracer method were overestimated, possibly by an average factor of $\sim 2$ as they were determined based on measured ambient OC/EC ratios during periods when ambient organic aerosol likely contained $\sim 50 \%$ SOA (see discussions in Sect. 3.4). Such underestimation of SOA (and overestimation of POA) would greatly diminish as the boundary layer rises, due to the strong dilution of EC. Since the $\mathrm{O}_{3}$ diurnal profile is anti-correlated to that of EC (due to the strong effect of the boundary layer on both), this would result in an apparent correlation between $\mathrm{SOA}$ and $\mathrm{O}_{3}$.

A related effect is illustrated in Fig. 2c where the organicsto-HOA ratio shows a pronounced daytime increase pattern that is similar to ozone $\left(r^{2}=0.38\right)$. Since the AMS cannot measure EC, the organics-to-HOA ratio is presented as a surrogate for the OC-to-EC ratio given the good correlation between HOA and EC (Fig. 2a) and between organic mass and OC concentrations $\left(r^{2}=0.88\right)$ (Zhang et al., 2005b). The observed daytime increase of organics-to-HOA ratio (as well as OC-to-EC ratio) is mainly driven by the strong diurnal variations in HOA (and EC) concentrations associated with daily fluctuation of the boundary layer height (Fig. 1b), rather than production of OOA.

Due to the good correlation between $\mathrm{SO}_{4}^{2-}$ and OOA $\left(r^{2}=0.74\right.$; Figs. $\left.2 \mathrm{~b}, 3 \mathrm{~d}\right)$ as well as the fact that both are in

\footnotetext{
${ }^{3}$ Dzepina, K., Zhang, Q., Salcedo, D., et al.: Characterization of ambient aerosol in Mexico City: The organic component, in preparation, 2005
}

the particle phase and are thus likely exposed to similar microphysical transformations and scavenging processes, $\mathrm{SO}_{4}^{2-}$ concentration is a better indicator for SOA concentration, at least during this study.

\subsubsection{Emission ratios of $\mathrm{HOA}$ and $\mathrm{OOA}-$ to- $\mathrm{SO}_{4}^{2-}$ ratio}

We examine here the emission ratios of HOA to primary pollutants for this study. The average ratio of HOA to EC is $\sim 1.41 \pm 0.22 \mu \mathrm{g} / \mu \mathrm{gC}$ during this study. It is similar to the average POA to EC ratio in the Northeast US estimated with a dispersion model $(=1.4 \mu \mathrm{g} / \mu \mathrm{gC})$ (Yu et al., 2004), as well as the value estimated from emission inventory during Pittsburgh summer time $(=1.2 \mu \mathrm{g} / \mu \mathrm{gC}$; calculated from Cabada et al., 2002).

The emission ratio of HOA to $\mathrm{CO}$ for this study, estimated after subtracting the Northern Hemisphere background of $\mathrm{CO}(0.1 \mathrm{ppm})$ from the measured $\mathrm{CO}$ concentrations, is $\sim 4.3 \mathrm{ng} \mathrm{m}^{-3} / \mathrm{ppbv}$. (The linear regression slope of HOA vs. CO with the intercept forced through zero is $\sim 3.7 \mathrm{ng} \mathrm{m}^{-3} / \mathrm{ppbv}$ ). These values are lower than the POA to $\mathrm{CO}$ emission ratio in New England $\left(9.4 \mathrm{ng} \mathrm{m}^{-3} / \mathrm{ppbv}\right)$ determined based on correlated behavior of total OA with gas-phase tracers (de Gouw et al., 2005) and the POA to CO ratio estimated from the AMS data in Tokyo, Japan $\left(11 \mathrm{ng} \mathrm{m}^{-3} / \mathrm{ppbv}\right.$ ) (Takegawa et al., 2005a $\mathrm{a}^{4}$. All of these numbers are larger than the average POA to $\mathrm{CO}$ emission ratios measured during a tunnel study in California $\sim 1.8 \mathrm{ng} \mathrm{m}^{-3} / \mathrm{ppbv}$ for diesel trucks and $\sim 0.8 \mathrm{ng} \mathrm{m}^{-3} / \mathrm{ppbv}$ for light-duty vehicles (calculated from Kirchstetter et al., 1999). In addition, the emission factor of $\mathrm{HOA}$ to $\mathrm{NO}_{\mathrm{x}}$ of this study (i.e., $42 \mathrm{ng} \mathrm{m}^{-3} / \mathrm{ppbv}$ ) is roughly 3 times the POA to $\mathrm{NO}_{\mathrm{x}}$ ratios of diesel trucks and light-duty vehicles (average $\approx 16$ and $11 \mathrm{ng} \mathrm{m}^{-3} / \mathrm{ppbv}$, respectively) from the California tunnel study (calculated from Kirchstetter et al., 1999). Possible reasons for the variations in these measured ratios include different sampling locations, seasons and meteorological conditions, different vehicle fleets (including different emission standards for California vehicles), as well as different measurement methods and assumptions applied for POA estimation.

Since sulfate is a better indicator for OOA concentration (see discussion above), we estimate the average concentration ratio of OOA to sulfate as 0.38 (dimensionless) during this study (Fig. 3d). The significance of this number is that it provides a first order estimation of the mass concentrations of OOA based on measured sulfate concentrations in fine particles in the Pittsburgh region during Fall. A survey of the $\mathrm{OOA}$ to $\mathrm{SO}_{4}^{2-}$ ratios based on AMS data at many locations

\footnotetext{
${ }^{4}$ Takegawa, N., Miyakawa, T., Kondo, Y., Jimenez, J. L., Worsnop, D. R., and Fukuda, M.: Seasonal and diurnal variations of submicron organic aerosols in Tokyo observed using the Aerodyne Aerosol Mass Spectrometer (AMS), J. Geophys. Res., submitted, 2005a.
} 


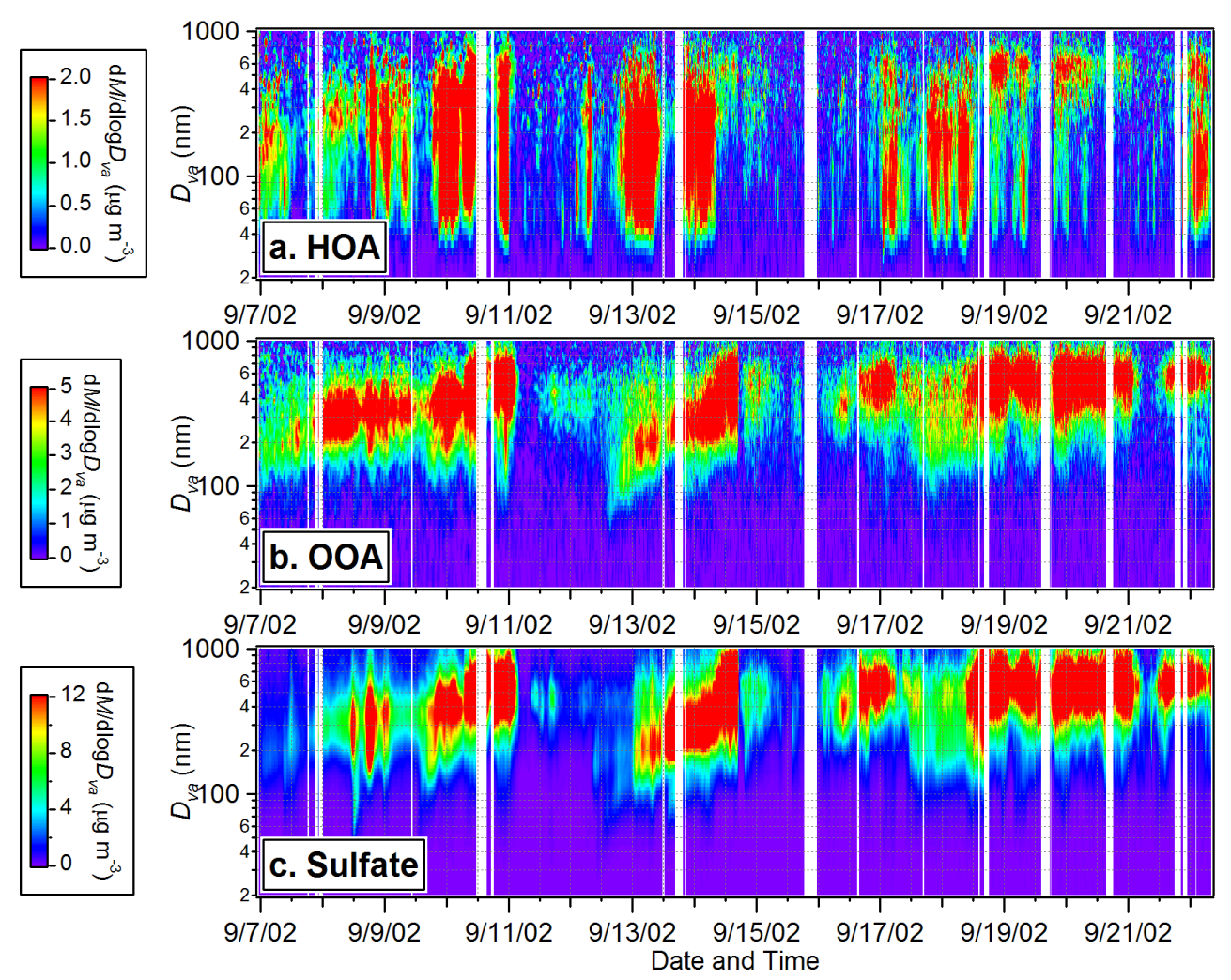

Fig. 4. Time variations of the size distributions of (a) HOA, (b) OOA, and (c) sulfate during 7-22 September 2002 in Pittsburgh. Missing data points are due to either occasional instrumental malfunction or maintenance/calibration.

in the Northern Hemisphere will be provided in a separate paper.

\subsection{Size distributions of HOA and OOA}

\subsubsection{Change of size distributions of HOA and OOA as function of time}

The image plots in Figs. 4a and b provide an overview of the temporal variations of the HOA and OOA size distributions during this study, showing again very different behaviors for HOA and OOA. OOA mostly resides in the accumulation mode with vacuum aerodynamic diameters $\left(D_{v a}\right.$; DeCarlo et al., 2004) larger than $250 \mathrm{~nm}$ while HOA displays a much broader distribution that extends into the ultrafine mode $\left(D_{v a}<100 \mathrm{~nm}\right)$. Typically $\sim 30 \%$ of the HOA mass is associated with ultrafine particles compared to less than $5 \%$ of the OOA mass.

Note that the AMS size distributions presented here are shown vs. $D_{v a}$, which is the aerodynamic diameter measured under free-molecular regime flow conditions. For a spherical particle, $D_{v a}$ equals the product of its physical diameter and density. Given that the average density of the bulk Pittsburgh particles was roughly 1.5 during this study (Zhang et al., 2005b, 2004), to a first approximation, $250 \mathrm{~nm}$ in $D_{v a}$ corre- sponds roughly to $170 \mathrm{~nm}$ in physical diameter for spherical particles.

The size distribution of OOA tracks the behavior of sulfate (and ammonium) throughout the entire study (Figs. 4b and c) (also see Zhang et al., 2005b and Suppl. Info), echoing the fact that their mass concentrations are highly correlated (Fig. 2; see Sect. 3.1). Simultaneous growth of OOA and $\mathrm{SO}_{4}^{2-}$ size distributions is observed during some periods, e.g., from the afternoon of 12 to 14 September - a period that follows an intense new particle formation event (see Sect. 3.5 for detailed discussion). These observations suggest that oxygenated organics are likely internally mixed with $\mathrm{NH}_{4}^{+}$and $\mathrm{SO}_{4}^{2-}$ and that both OOA and $\mathrm{SO}_{4}^{2-}$ are formed over similar regional scales. The HOA size distribution pattern is distinctly different from those of $\mathrm{OOA}$ and $\mathrm{SO}_{4}^{2-}$. It is generally much broader, showing a pronounced ultrafine mode that increases at night and in the morning. On average, only $\sim 50 \%$ of the total HOA mass is associated with the accumulation mode.

Figure 5a summarizes the average size distributions of HOA, OOA, and inorganic aerosols species of the entire study that again demonstrate the overall resemblance of OOA to secondary aerosol species $\left(\mathrm{NH}_{4}^{+}, \mathrm{SO}_{4}^{2-}\right.$, and $\left.\mathrm{NO}_{3}^{-}\right)$. Compared to the size distributions of $\mathrm{SO}_{4}^{2-}$ and $\mathrm{NH}_{4}^{+}$, those of $\mathrm{OOA}$ and $\mathrm{NO}_{3}^{-}$are slightly broader, extending more into the 
smaller sizes $(<300 \mathrm{~nm})$. In the case of nitrate, this likely reflects active gas-particle partitioning due to its semivolatile character and the strong influences of ambient temperature and relative humidity on the partitioning (Seinfeld and Pandis, 1998). Similarly, the broader OOA distribution suggests a stronger influence of local gas-to-particle partitioning on OOA than on $\mathrm{NH}_{4}^{+}$and $\mathrm{SO}_{4}^{2-}$ formation. This is consistent with the known semivolatile character of some SOA compounds (Sheehan and Bowman, 2001), compared to the nonvolatile character of sulfates. Figure $5 \mathrm{~b}$ shows the average fractional contributions of HOA and OOA to total organic mass as a function of aerosol size, from which we estimate that $\sim 75 \%$ of the accumulation mode organic mass is OOA. In contrast, $\sim 75 \%$ of the organic mass in ultrafine aerosols is HOA.

\subsubsection{Diurnal variations of the size distributions}

The average diurnal image plots of the HOA, OOA, and sulfate size distributions are shown in Fig. 6. As pointed out in Sect. 3.1, the dip at 17:00 18:00 EST on the diurnal plots of OOA and sulfate is primarily due to a rainfall event in the afternoon of 15 September. These figures are analogous to Fig. 4, showing that HOA has distinctly different behavior than OOA and $\mathrm{SO}_{4}^{2-}$ and that the highest OOAto-organics fraction (and the accompanying shift of particles toward larger sizes) preferentially occurs in the afternoon. Figure 7 provides a survey of the average size distributions of HOA and OOA and their relative contributions to the total organic mass during different hours of the day in correspondence to Fig. 6. Even in early afternoon, when the HOA mass loading is the lowest and its size distribution the narrowest, the ultrafine mode organics are about 50\% HOA.

\subsubsection{Size distributions of HOA and OOA for periods with different HOA and OOA fractions}

We display in Fig. 8 the average size distributions of HOA and OOA and the correlations of HOA to $\mathrm{CO}$ and OOA to $\mathrm{SO}_{4}^{2-}$ during: 1) high $\mathrm{HOA}$ and $\mathrm{CO}$ periods (when both $\mathrm{HOA}$ and $\mathrm{CO}$ are in the upper 75th percentile of their absolute concentrations) that represent the situation of intense primary combustion emissions and high loading of fresh organic aerosols; 2) "typical" situation when the fractional contribution of OOA to the total organics (OOA\%) is within the 25th-75th percentile of its absolute values (corresponding to periods when OOA contributes $58 \% \sim 81 \%$ of the total organic mass); and 3) aged aerosol periods when OOA\% are in the top 25th percentile of its absolute values (corresponding to periods when OOA contributes more that $81 \%$ of the total organic aerosol mass). In general, there is a clear shift of all species (including, $\mathrm{SO}_{4}^{2-}$, $\mathrm{OOA}$, and most dramatically HOA) to larger mode size with higher OOA fraction (e.g., Fig. 8a-1 vs. Fig. 8c-1). The size distribution of HOA demonstrates an increasingly prominent accumulation mode

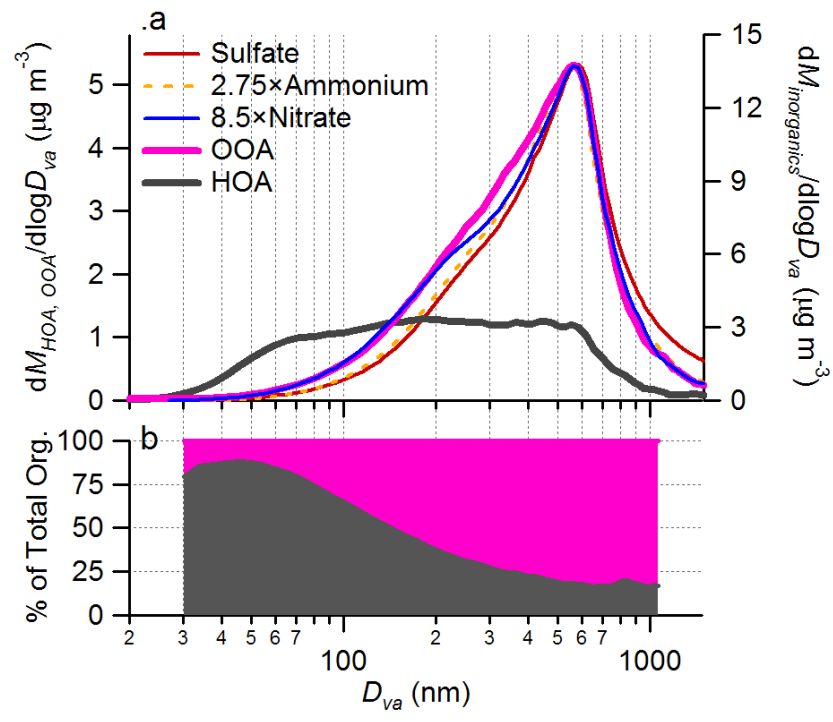

Fig. 5. (a) Average size distributions of $\mathrm{HOA}, \mathrm{OOA}$, and particle phase inorganic ions $\left(\mathrm{NH}_{4}^{+}, \mathrm{NO}_{3}^{-}\right.$, and $\left.\mathrm{SO}_{4}^{2-}\right)$ and (b) the size resolved fractional contributions of HOA and OOA to total organic aerosols in Pittsburgh over the entire study (7-22 September 2002).

with higher OOA fraction. Note that although part of the narrowing of OOA distribution observed could be due to limited transmission of the AMS lens at high particle sizes (Jayne et al., 2000; and see discussions in Zhang et al., 2005b), such effect is expected to be fairly small during this study since the majority of Pittsburgh organic mass is in submicron aerosols (Cabada et al., 2004b).

In addition, there are several trends observed: (1) the size distributions of OOA and $\mathrm{SO}_{4}^{2-}$ are very similar under all situations; (2) HOA always dominates the composition of small particles $\left(D_{v a}<100 \mathrm{~nm}\right)$, even during very high OOA periods (Fig. 8c-1); 3) the linear regression slope of HOA vs. CO is somewhat lower with higher OOA fraction (Figs. 8b-1-8b3 ); and 4) the correlation of OOA to $\mathrm{SO}_{4}^{2-}$ is always good but the $\mathrm{OOA} / \mathrm{SO}_{4}^{2-}$ ratio decreases slightly with high OOA fraction (Figs. 8c-1-8c-3). In addition, while not shown here, the correlation of $\mathrm{OOA}$ with $\mathrm{O}_{3}$ does not improve (i.e., $r^{2} \approx 0$ ) at high OOA.

\subsection{Mass spectra and estimated elemental compositions of HOA and OOA}

Together with the mass concentrations of HOA and OOA, complete mass spectra of these two components were extracted using the deconvolution technique described in Zhang et al. (2005a). Because of the clear separation of the HOA signals from the OOA in measured mass spectra, we are able to estimate the possible elemental compositions of each $m / z$ in the HOA and OOA spectra and thus the elemental composition of the organic aerosol. Table 2 lists the estimated compositions of the 14 and 16 most abundant $m / z$ 's, 


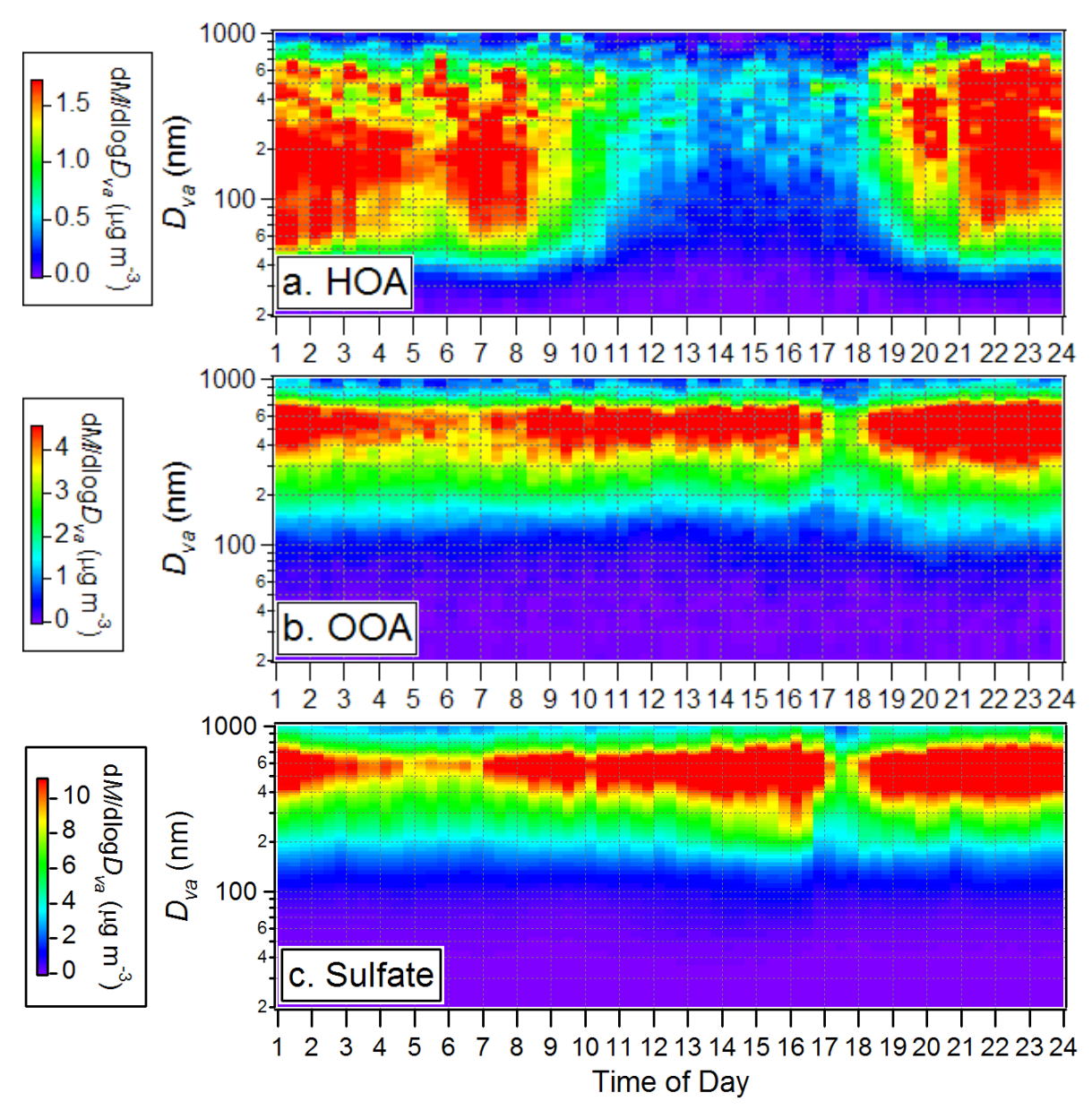

Fig. 6. Average diurnal variations of the size distributions of (a) HOA, (b) OOA, and (c) sulfate during 7-22 September 2002 in Pittsburgh. The raw data have been averaged into 20 min intervals.

accounting for $75 \%$ and $67 \%$ of the OOA and HOA signals, respectively. The assumed compositions of the major peaks in the spectra were verified by examining preliminary data on the organic mass spectra of ambient aerosols acquired by a high-resolution ToF-AMS ${ }^{5}$. For $m / z$ 's not listed in the table, we assume that those of HOA have the same average $\mathrm{C}: \mathrm{H}$ ratio as the average of $16 \mathrm{HOA} \mathrm{m} / \mathrm{z}$ 's listed in Table 2 (i.e., average molecular composition is $\left.\left(\mathrm{CH}_{2}\right)_{n}\right)$ and those of OOA have an average $\mathrm{C}: \mathrm{H}: \mathrm{O}$ ratio same as the average of the major OOA $\mathrm{m} / \mathrm{z}$ 's in Table 2 excluding 17, 18, 28 and 44 (i.e., average molecular composition is $\left.\left(\mathrm{C}_{2} \mathrm{H}_{3} \mathrm{O}\right)_{n}\right)$.

These elemental compositions are first order estimations since we only included $\mathrm{C}, \mathrm{H}$, and $\mathrm{O}$ atoms. The omission of nitrogen atom may influence the OM:OC estimates since nitrogen-containing organic compounds have been detected in ambient aerosols ( $\mathrm{Li}$ and $\mathrm{Yu}, 2004$; Zhang and Anastasio, 2003; Zhang et al., 2002a, b]. However, the influence is expected to be relatively small because $\mathrm{C}, \mathrm{H}$, and $\mathrm{O}$ are

\footnotetext{
${ }^{5}$ DeCarlo, P., Aiken, A., Jimenez, J. L., et al.: A HighResolution Aerosol Mass Spectrometer, in preparation, 2005.
}

the three dominant atoms reported in aerosol organic species (Seinfeld and Pandis, 1998). Recent studies reported that $\mathrm{N}$ atoms typically account for $10 \%$ or less of the total organic mass in atmospheric fine particles and fog waters (e.g., Zhang and Anastasio, 2001; Zhang et al., 2002a). In addition, by using mass spectra to derive the elemental composition of molecules (Table 2) we assume that the elemental composition of the ions is on average the same as the elemental composition of the parent molecules. This assumption could introduce some bias on the estimated elemental composition if certain functional groups or molecular structures have a greater tendency to end up as either ions or neutrals in the fragmentation process.

Figure 9 shows mass spectra of HOA and OOA colored with the contribution of $\mathrm{C}, \mathrm{H}$, and $\mathrm{O}$ at each $\mathrm{m} / z$. See Zhang et al. (2005a) for detailed discussion on these two mass spectra; only the major points are summarized here: 1) the HOA spectrum demonstrates prominent ion series characteristic of hydrocarbons and shows remarkable similarity to the measured AMS mass spectra of diesel exhaust aerosols and lab-generated lubricating oil and diesel fuel aerosols 

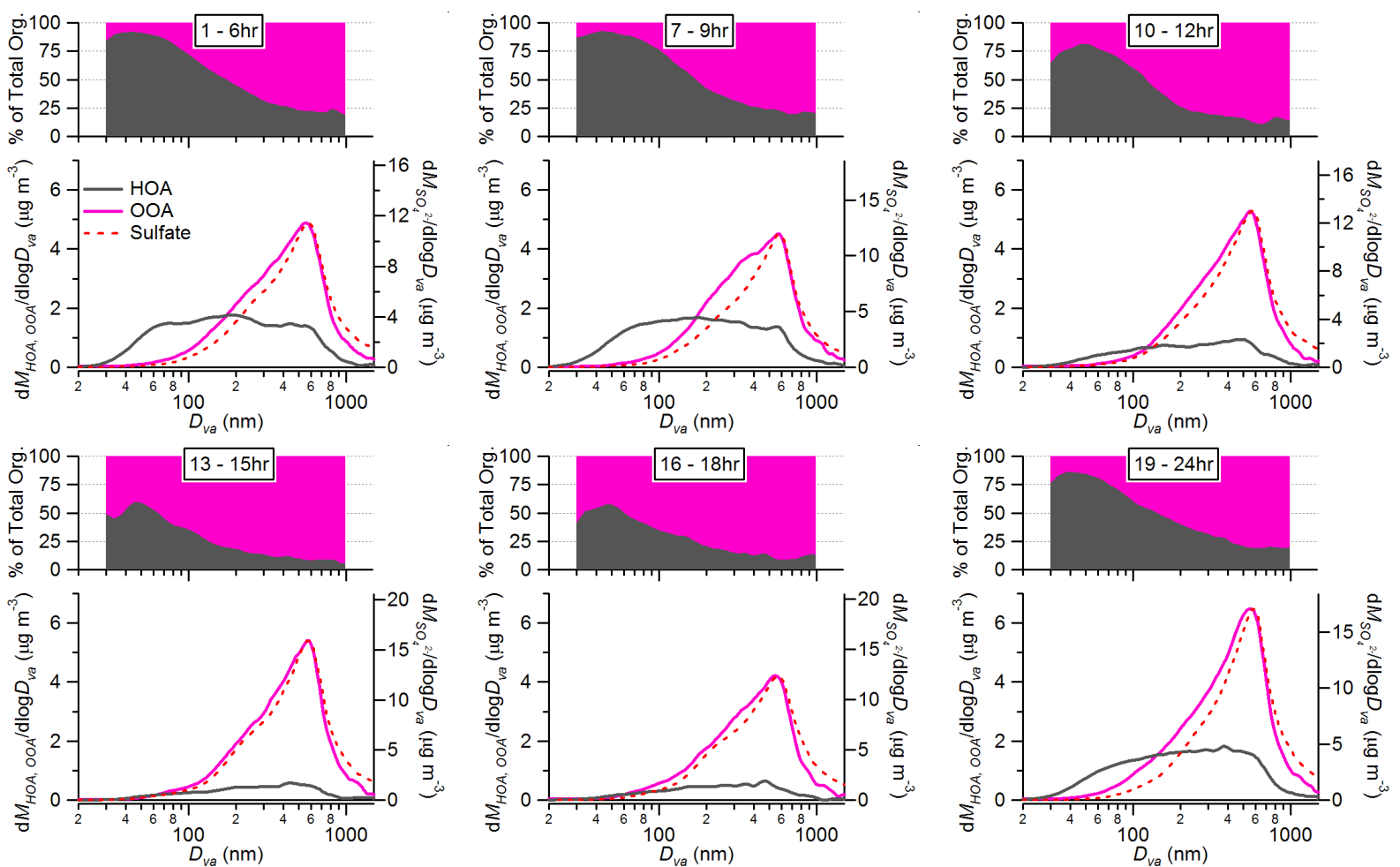

Fig. 7. Average size distributions of HOA, OOA and sulfate and the size resolved fractional distributions of HOA and OOA to total organics during different hours of day.

Table 2. Estimated elemental compositions of the major $m / z$ 's (total number=270) in HOA and OOA ${ }^{\text {a }}$.

\begin{tabular}{|c|c|c|c|c|c|}
\hline$m / z$ & $\begin{array}{l}\text { HOA } \\
\% \text { Sig. }\end{array}$ & $m / z$ Comp. & $m / z$ & $\begin{array}{l}\text { OOA } \\
\% \text { Sig. }^{b}\end{array}$ & $m / z$ Comp. \\
\hline 27 & 3.2 & $\mathrm{C}_{2} \mathrm{H}_{3}$ & 15 & 3.9 & $\mathrm{CH}_{3}$ \\
\hline 29 & 3.4 & $\mathrm{C}_{2} \mathrm{H}_{5}$ & 17 & 2.8 & $\mathrm{HO}$ \\
\hline 41 & 7.5 & $\mathrm{C}_{3} \mathrm{H}_{5}$ & 18 & 11.2 & $\mathrm{H}_{2} \mathrm{O}$ \\
\hline 42 & 1.4 & $\mathrm{C}_{3} \mathrm{H}_{6}$ & 27 & 4.9 & $\mathrm{C}_{2} \mathrm{H}_{3}$ \\
\hline 43 & 10.8 & $\mathrm{C}_{3} \mathrm{H}_{7}$ & 28 & 14.6 & $\mathrm{CO}$ \\
\hline 55 & 9.2 & $\mathrm{C}_{4} \mathrm{H}_{7}$ & 29 & 7.4 & $\mathrm{CHO}$ \\
\hline 56 & 2.1 & $\mathrm{C}_{4} \mathrm{H}_{8}$ & 31 & 2.2 & $\mathrm{CH}_{3} \mathrm{O}$ \\
\hline 57 & 7.8 & $\mathrm{C}_{4} \mathrm{H}_{9}$ & 41 & 2.8 & $\mathrm{C}_{2} \mathrm{HO}$ \\
\hline 67 & 2.9 & $\mathrm{C}_{5} \mathrm{H}_{7}$ & 42 & 2.9 & $\mathrm{C}_{2} \mathrm{H}_{2} \mathrm{O}$ \\
\hline 69 & 4.9 & $\mathrm{C}_{5} \mathrm{H}_{9}$ & 43 & 6.4 & $\mathrm{C}_{2} \mathrm{H}_{3} \mathrm{O}$ \\
\hline 71 & 3.1 & $\mathrm{C}_{5} \mathrm{H}_{11}$ & 44 & 11.2 & $\mathrm{CO}_{2}$ \\
\hline 81 & 2.5 & $\mathrm{C}_{6} \mathrm{H}_{9}$ & 45 & 1.5 & $\mathrm{CO}_{2} \mathrm{H}$ \\
\hline 83 & 2.5 & $\mathrm{C}_{6} \mathrm{H}_{11}$ & 53 & 1.5 & $\mathrm{C}_{3} \mathrm{HO}$ \\
\hline 85 & 1.6 & $\mathrm{C}_{6} \mathrm{H}_{13}$ & 55 & 1.5 & $\mathrm{C}_{3} \mathrm{H}_{3} \mathrm{O}$ \\
\hline 95 & 2.1 & $\mathrm{C}_{7} \mathrm{H}_{11}$ & & & \\
\hline 97 & 1.6 & $\mathrm{C}_{7} \mathrm{H}_{13}$ & & & \\
\hline rest of $m / z$ 's & 33 & $\left(\mathrm{CH}_{2}\right)_{n}^{\mathrm{c}}$ & rest of $m / z$ 's & 25 & $\left(\mathrm{C}_{2} \mathrm{H}_{3} \mathrm{O}\right)_{n}^{\mathrm{d}}$ \\
\hline
\end{tabular}

a The mass spectra of HOA and OOA (up to $m / z=150$ ) are presented in Fig. 7 and those in logarithmic scale (to show low signal $m / z$ 's more clearly) are presented in Fig. 11 in Zhang et al. (2005a).

$\mathrm{b} \%$ of the total signals in each component (HOA or OOA) mass spectrum that was detected at the specified $m / z$.

c Average molecular composition assumed for the rest of the HOA $m / z$ 's.

d Average molecular composition assumed for the rest of the OOA $m / z$ 's. 

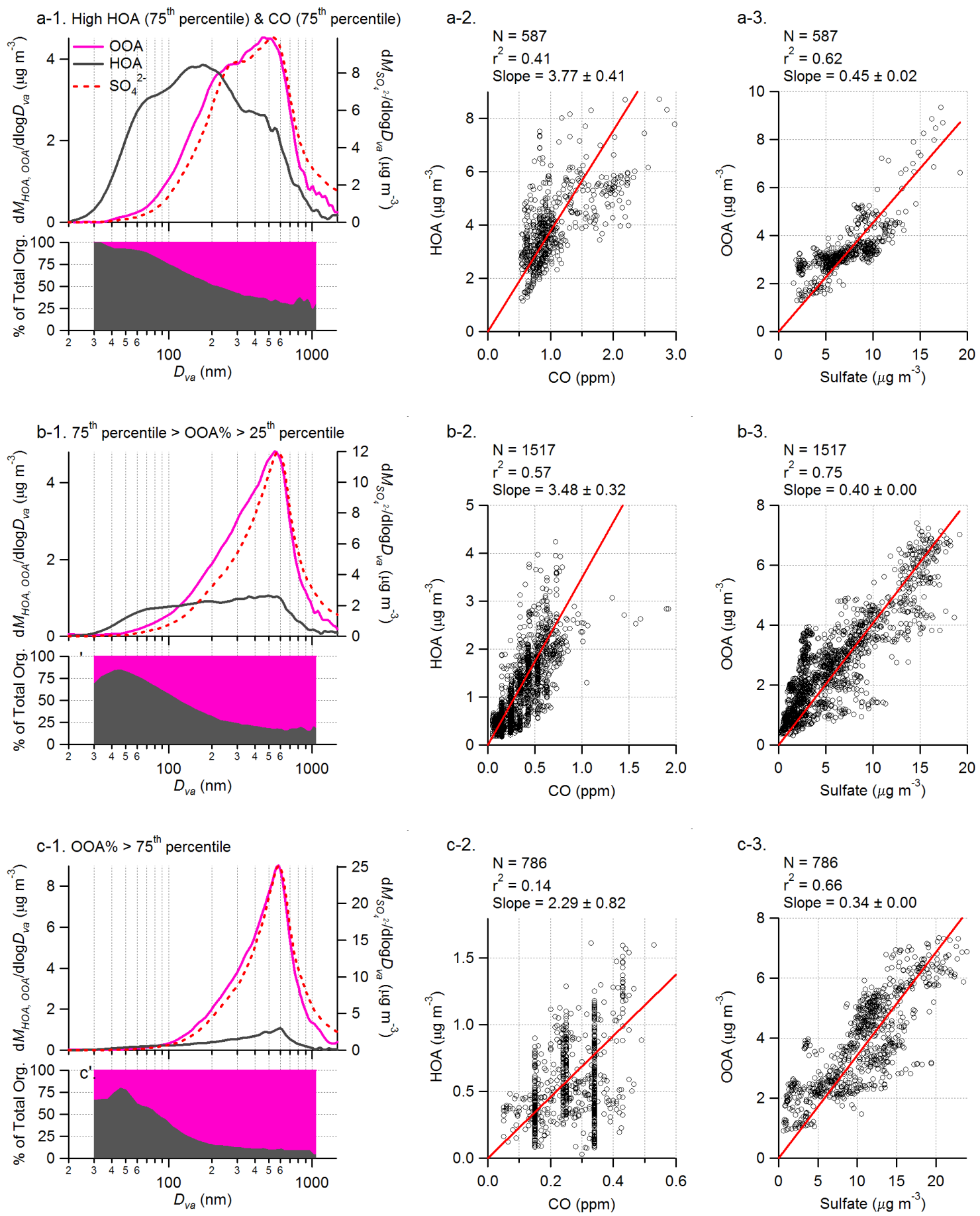

Fig. 8. Average size distributions and the size resolved fractional contributions of HOA and OOA to total organic aerosols during: (a-1) High HOA (above 75th percentile of HOA concentration) and CO (above 75th percentile CO concentration) periods; (b-1) Periods when the OOA to total organics ratios (OOA\%) are within the 25th-75th percentile of its value and (c-1) Periods when OOA\% are in top 75th percentile the value. To the right of the size distribution plots are the scatter plots and linear regressions between HOA and CO (a-2, b-2 and c-2) and OOA vs. sulfate (a-3, b-3 and c-3) during the corresponding periods. Red lines are the linear fits to the data. All the linear fits were performed with intercept forced through the origin. 

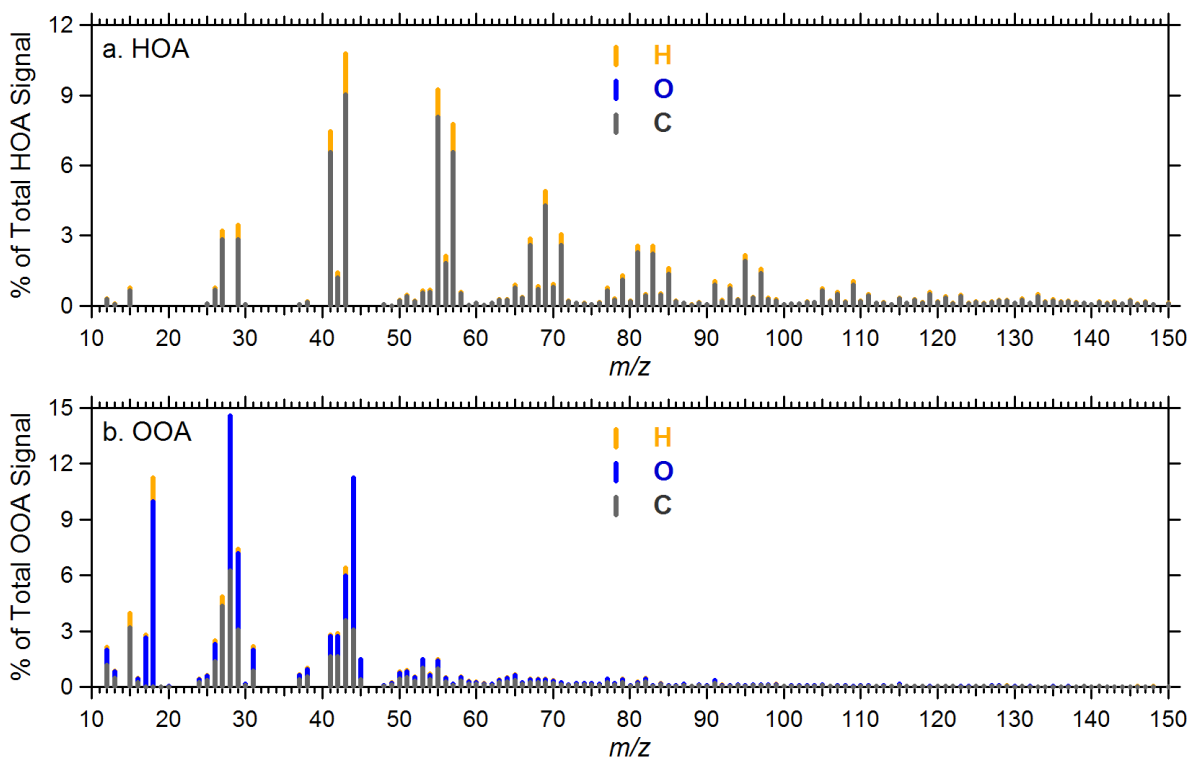

Fig. 9. Mass spectra of (a) HOA and (b) OOA, colored with the estimated contribution of each element (C, H, and O) to the mass of each $m / z$ fragment. The elemental compositions of each $m / z$ in HOA and OOA are estimated according to Table 2.

(Canagaratna et al., 2004); 2) the OOA spectrum is dominated by $m / z 44\left(\mathrm{CO}_{2}^{+}\right)$and $m / z 28\left(\mathrm{CO}^{+}\right)$and demonstrates close similarity in the overall pattern with those of aged/oxidized organic aerosols in rural and urban areas; and 3) the OOA spectrum is also qualitatively similar to the AMS mass spectrum of Suwannee River fulvic acid (Alfarra, 2004), which is a class of highly oxygenated organic compounds that have been proposed as models of the highly oxidized organic aerosols that are ubiquitous in the atmosphere (Decesari et al., 2002). In addition, neither HOA nor OOA mass spectrum represents individual species, but rather, they represent mixtures of many individual organic species associated with the same group of sources and atmospheric processes (i.e., urban emissions vs. regional secondary aerosol).

Based on estimated elemental compositions of $m / z$ 's, we estimate that the average molar ratio of $\mathrm{C}: \mathrm{H}: \mathrm{O}$ in OOA is $1: 1.6: 0.8$ (or 5:8:4) and that the average molar ratio of $\mathrm{C}: \mathrm{H}$ in HOA is $1: 1.9$ (or 10:19). The organic mass to organic carbon ratios (OM:OC) of HOA and OOA are estimated at 1.2 and $2.2 \mu \mathrm{g} / \mu \mathrm{gC}$, respectively. This HOA $\mathrm{OM}: \mathrm{OC}$ ratio is consistent with the value $(1.2 \mu \mathrm{g} / \mu \mathrm{gC})$ of hydrocarbons (Turpin and Lim, 2001) - the major components of urban fresh combustion aerosols. In addition, the OOA OM:OC ratio is close to the value estimated for nonurban aerosols $(2.1 \pm 0.2 \mu \mathrm{g} / \mu \mathrm{gC})$ (Turpin and Lim, 2001) but is significantly higher than estimates based on functional group measurements by FTIR spectroscopy for samples collected in northeastern Asia and the Carribean (1.2-1.6, mean $\approx 1.4 \mu \mathrm{g} / \mu \mathrm{gC}$ ) (Russell, 2003).

The average OM:OC ratio of submicron organic aerosols (OOA plus HOA) estimated with this procedure is $\sim 1.8$, a

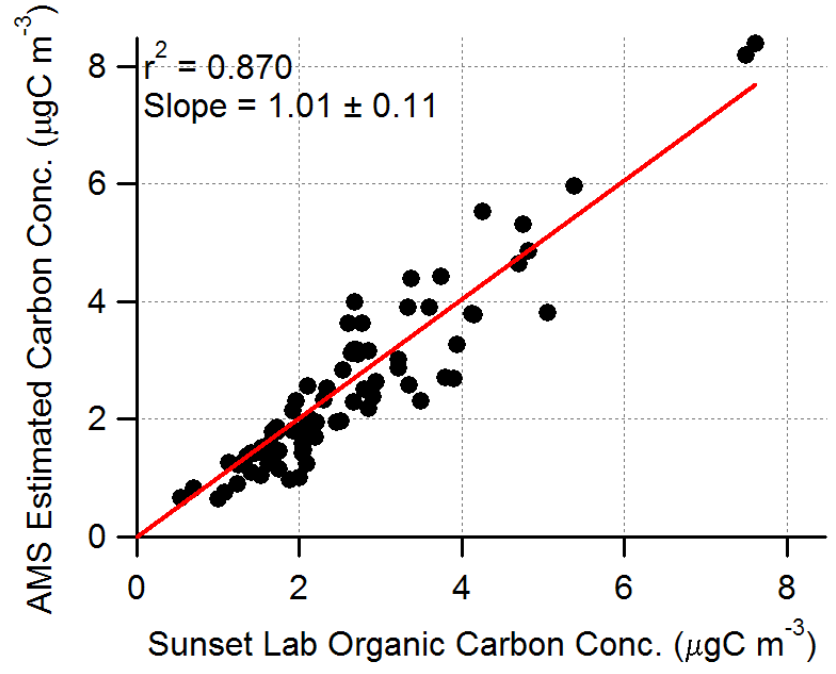

Fig. 10. Scatter plot between organic carbon concentrations estimated from AMS mass spectra and component-specific $m / z$ elemental compositions, and those measured by the Sunset Lab carbon analyzer.

value that is close to the number determined by comparing organic mass concentration from the AMS and organic carbon concentration from a Sunset labs carbon analyzer (Zhang et al., 2005b). It is also comparable to the number $(1.6 \pm 0.2)$ proposed by Turpin and Lim (2001) for urban aerosols. This analysis is summarized in Fig. 10, where the organic carbon contents derived from the HOA and OOA mass spectral analysis show good agreement with the organic carbon (OC) concentrations from the carbon analyzer $\left(r^{2}=0.87\right.$ and the linear regression slope $=1.01 \pm 0.11$ ). 

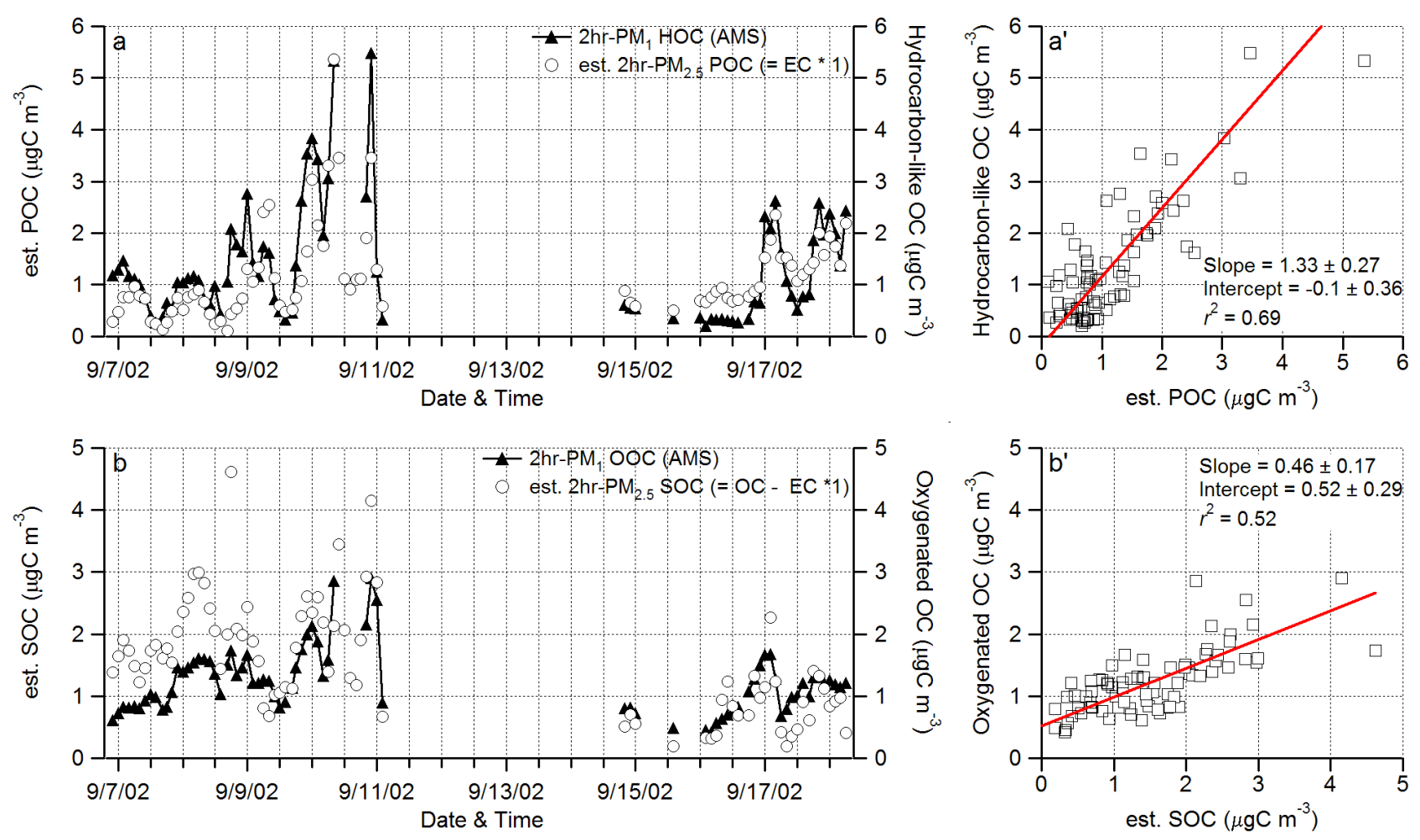

Fig. 11. (a) and (a') Time series, scatter plot and linear regression between (a) \& (a') hydrocarbon-like organic carbon (HOC) concentrations from the AMS measurements and primary organic carbon (POC) concentrations estimated from the EC measurements assuming a POC to EC ratio of 1 and (b) \& (b') oxygenated organic carbon (OOC) concentrations and secondary organic carbon concentrations $(\mathrm{SOC}=\mathrm{OC}-$ POC). AMS HOA and OOA data were reduced to $2 \mathrm{~h}$ averages according to EC/OC measurement time intervals. Missing data during 11 September-15 September were due to malfunction of the Sunset Laboratory carbon analyzer. The linear regression parameters and $r^{2}$ 's are shown in the scatter plots.

\subsection{Comparison with results from previous studies}

\subsubsection{Comparison with estimates from the EC/OC tracer method}

The elemental carbon (EC)/organic carbon (OC) tracer method has been frequently used to estimate the carbon concentrations of primary and secondary organic aerosol (POC and SOC, respectively) (Cabada et al., 2002, 2004a; Castro et al., 1999; Park et al., 2005; Polidori et al., 2005²; Turpin and Huntzicker, 1991, 1995). This method derives the POC concentration based on the EC measurements assuming a constant POC to EC ratio (Turpin and Huntzicker, 1991, 1995). SOC is subsequently estimated as the difference between measured total $\mathrm{OC}$ and the estimated POC based on the assumption that SOA is formed through gas to particle conversion that involves no EC emissions. Note that the POC and SOC concentrations thus estimated may contain significant uncertainties due to 1) the operational definition for the OC and EC fractions in thermal-optical analysis (Gelencser, 2004; Turpin et al., 2000); 2) the uncertainties associated with the estimated POC/EC ratios for the average of the combustion emission sources (Turpin and Lim, 2001); and 3) variations in time of POC/EC ratios due to factors such as varying fractions of diesel and gasoline vehicles on the road (Harley et al., 2005). Despite these limitations, the EC/OC method has been applied frequently because of the lack of direct measurement techniques that can distinguish POA from SOA (Kanakidou et al., 2005).

The POC and SOC concentrations during this study are estimated using the $\mathrm{PM}_{2.5} \mathrm{EC}$ and $\mathrm{OC}$ data from thermaloptical transmittance carbon analysis (Polidori et al., 2005 ${ }^{2}$ ): $\mathrm{POC}=1 \times \mathrm{EC}$ and $\mathrm{SOC}=\mathrm{OC}-\mathrm{POC}$. The POC/EC ratio of 1 was estimated based on summertime emission inventories in Pittsburgh (Cabada et al., 2002). Figure 11 compares the POC and SOC estimates to the concentrations of hydrocarbon-like and oxygenated organic carbon (HOC and OOC, respectively) estimated according to their estimated molecular compositions (see Sect. 3.3). Overall, HOC correlates well to POC $\left(r^{2}=0.69\right.$, Figs. 11a and 11a') and OOC correlates with SOC $\left(r^{2}=0.52\right.$; Figs. $11 \mathrm{~b}$ and $\left.11 \mathrm{~b}^{\prime}\right)$. These correlations are consistent with the diurnal variation patterns, mass spectra, and size distributions of HOA and OOA, which all corroborate the hypothesis that most or all HOA is POA and that most or all OOA is SOA. 
(a) AMS estimates

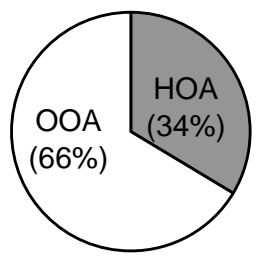

(b) $\mathrm{POC}: \mathrm{EC}=1.2: 1$

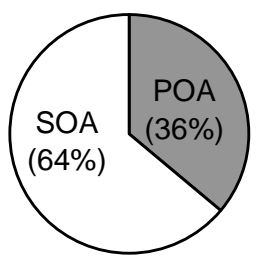

(c) $P O C: E C=1: 1$

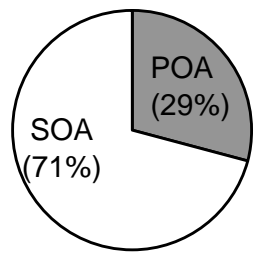

(d) POC:EC $=2: 1$

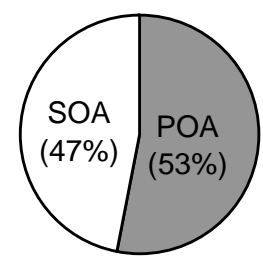

Fig. 12. Fractional distributions of (a) HOA and OOA estimated from the AMS data and POA and SOA estimated from OC/EC measurements assuming POC-to-EC ratio $(\mathbf{b})=1.2,(\mathbf{c})=1$ and $(\mathbf{d})=2$. POA and SOA are converted from POC and SOC assuming OM:OC ratios of $1.2 \mu \mathrm{g} \mathrm{m}^{-3} / \mu \mathrm{gC} \mathrm{m}^{-3}$ and $2.2 \mu \mathrm{g} \mathrm{m}^{-3} / \mu \mathrm{gC} \mathrm{m}^{-3}$, respectively.

The linear regression fit to $\mathrm{HOC}$ vs. POC has a slope of $1.33 \pm 0.27 \mu \mathrm{gC} / \mu \mathrm{gC}$ ) and an intercept of $-0.10 \pm 0.36 \mu \mathrm{gC} \mathrm{m}^{-3}$ (Fig. 11a). In contrast, the fit to OOC vs. SOC yields slope $=0.46 \pm 0.17 \mu \mathrm{gC} / \mu \mathrm{gC}$ with intercept of $0.52 \pm 0.29 \mu \mathrm{gC} \mathrm{m}^{-3}$. The slopes of HOC vs. POC and OOC vs. SOC obtained with the intercept fixed at zero are $1.23 \pm 0.22$ and $0.74 \pm 0.35$, respectively. Note that perfect agreement between these two estimates of POC and SOC is not expected because they were estimated by completely different methods under different assumptions. In addition, uncertainties associated with both measurements and data analysis procedures may also contribute to the observed discrepancy. For instance, there appear to be some changes in the correlation patterns after 11 to 14 September - a gap of missing POC and SOC data due to a major component failure of the EC/OC analyzer (J. Cabada, Tecnológico de Monterrey, personal communication).

As pointed out at the beginning of this section, the soundness of the OC/EC method for predicting POC and SOC is strongly influenced by the choice of the POC to EC ratio and the validity of the assumption that this ratio is relatively constant during the time period of interest. To illustrate this first point, we compare in Fig. 12 the fractional distribution of POA and SOA obtained from the AMS data to those obtained from the EC/OC tracer method using different $\mathrm{POC}$ to $\mathrm{EC}$ ratios: 1) $\mathrm{POC} / \mathrm{EC}=1.2$, which is the average $\mathrm{HOC}$ to $\mathrm{EC}$ ratio estimated from this study; 2) $\mathrm{POC} / \mathrm{EC}=1$, which is estimated based on emission inventory for Pittsburgh in the summer (Cabada et al., 2002); and 3) $\mathrm{POC} / \mathrm{EC}=2$, which is approximately the average of a range of ratios estimated based on measured $\mathrm{OC} / \mathrm{EC}$ ratios during periods dominated by primary emissions and with low $\mathrm{O}_{3}$ (Cabada et al., 2004a; Polidori et al., 2005 ${ }^{2}$ ). POA and SOA are estimated from the POC and SOC results of the EC/OC method assuming OM:OC ratios of $1.2 \mu \mathrm{g} \mathrm{m}^{-3} / \mu \mathrm{gC} \mathrm{m}^{-3}$ and $2.2 \mu \mathrm{g} \mathrm{m}^{-3} / \mu \mathrm{gC} \mathrm{m}^{-3}$, respectively (see Sect. 3.3).

As shown in Figs. 12a and b, the fractional distribution of POA/SOA estimated from EC/OC measurements agrees very well to that determined from the AMS data when $\mathrm{POC} / \mathrm{EC}=1.2$ is used. In comparison, assuming $\mathrm{POC} / \mathrm{EC}=1$ yields higher fraction of SOC (Fig. 12c) while assuming
$\mathrm{POC} / \mathrm{EC}=2$ projected from ambient measurements leads to significantly less SOC and twice more POC (Fig. 12d). Note that $\mathrm{POC} / \mathrm{EC}=2$ may be a significant overestimation since fine particles in Pittsburgh are strongly influenced by regional sources and thus contain a relatively high background of oxidized organic species (Anderson et al., 2004; Tang et al., 2004; Zhang et al., 2005b). Even during periods with intense primary emissions and reduced mixing (e.g., morning rush hour) OOA contributes more than $50 \%$ of the total organic mass on average (Fig. 1). In addition, a low concentration of $\mathrm{O}_{3}$ does not necessarily imply that SOA is also low because $\mathrm{O}_{3}$ is a much shorter-lived photochemical product than $\mathrm{SOA} . \mathrm{O}_{3}$ can be titrated away quickly by $\mathrm{NO}$ emitted by traffic, while SOA will persist. Figure 3d, for example, shows that the $r^{2}$ between OOA and $\mathrm{O}_{3}$ is almost zero during this study (see Sect. 3.1.2). In fact, based on the OOA/HOA ratios observed during the morning rush hour $(\sim 1.3: 1)$, we estimate that the POC/EC assumptions projected from ambient measurements in Pittsburgh may be biased high by up to a factor of 2 , suggesting that $\mathrm{POC} / \mathrm{EC} \sim 1$ is a better estimate. In addition, these comparisons, together with the good correlation between $\mathrm{HOA}$ and $\mathrm{EC}$, also indicate that the $\mathrm{EC} / \mathrm{OC}$ tracer method can produce a useful estimation of $\mathrm{POC}$ and $\mathrm{SOC}$ as long as the correct $\mathrm{POC} / \mathrm{EC}$ ratio is given. Otherwise, the POC and SOC estimates can have considerable errors if this ratio is not well constrained (as is often the case in practice).

\subsubsection{Comparison with results from VOC-based factor analysis}

Millet et al. (2005) also estimated the fraction of secondary carbon in Pittsburgh aerosols during July-August 2002, based on a new hybrid source apportionment method incorporating elements of the EC/OC tracer method and of joint factor analysis of a large set of VOCs. These authors estimate an OC/EC ratio of 1.36 for primary combustion emissions, in qualitative agreement with our results discussed in the previous section. They also estimate that secondary organic carbon contributed $37 \%$ of the total carbon, while $35 \%$ of the carbon was classified as regional background. 


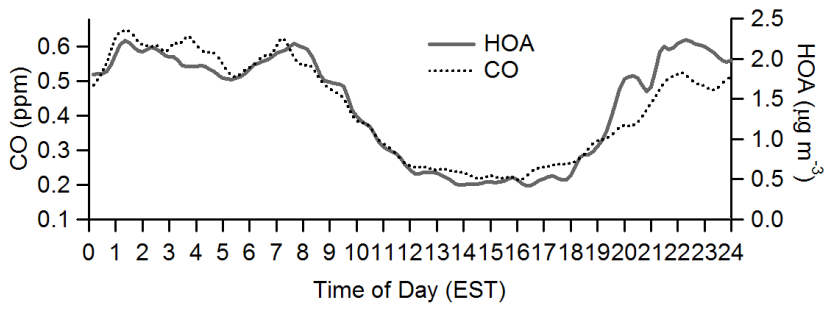

Fig. 13. Average diurnal profiles of HOA mass concentrations and CO during 7-22 September 2002 in Pittsburgh.

It is likely that the secondary OC estimated by Millet et al. was primarily oxygenated given the high similarity between the mass spectra of SOA and OOA in Pittsburgh (see Sect. 3.5.2). It is also likely that the majority of the regional background OC from Millet et al. study was oxygenated, because 1) OOA on average accounts for $80 \%$ of the total OA in afternoon and 2) the diurnal profile of OOA concentration is relatively flat in Pittsburgh (Fig. 2), which suggests relatively small local production of OOA in comparison to the regional contribution (see discussion in Sect. 3.1). We therefore estimate that "secondary" and "background" carbon in the Millet et al. study (which in total accounts for $72 \%$ of the OC during their study) was mostly oxygenated. This fraction is even larger than the OOC fraction we estimated for the present study (see Fig. 12), which may be due to the reason that the Millet et al. study took place in the middle of the Summer when photochemical activity and SOA production was higher than for our study period at the end of the Summer.

\subsection{Sources and processes of HOA and OOA}

As discussed above, the diurnal variations, size distributions and mass spectra of HOA and OOA and their correlations with combustion and secondary aerosol tracers all suggest that HOA are mainly primary organic aerosols from combustion processes while OOA are mostly produced from secondary processes. In this section, we will examine the evolution of HOA and OOA and gain further insights into the possible sources and processes of these two aerosol types.

\subsubsection{HOA aging and processing}

Recent studies have suggested that primary organic aerosols may undergo substantial photochemical oxidation and might contribute significantly to the oxygenated OA pool in urban particles (Robinson et al., 2005). To evaluate this point, in Fig. 13 we compare the diurnal profiles of HOA and $\mathrm{CO}$ under the consideration that $\mathrm{CO}$ is a comparatively long-lived tracer of combustion emissions (cf. 1 month lifetime in the troposphere; Finlayson-Pitts and Pitts, 2000). On this plot, the $\mathrm{y}$-axes of HOA and $\mathrm{CO}$ are scaled from zero and $100 \mathrm{ppb}$ (the background level of $\mathrm{CO}$ in Northern Hemisphere), re- spectively, to their morning maxima. The rationale behind this figure is that significant HOA oxidation would appear as a lowering of the HOA/CO ratio during photochemically active periods (e.g., between 13:00-15:00 EST), assuming relatively constant $\mathrm{HOA}$ to $\mathrm{CO}$ emission ratios throughout the day.

The synchronous decrease in the concentrations of $\mathrm{CO}$ and HOA around 07:00-08:00 a.m. is primarily the result of atmospheric dilution due to increasing mixed layer height. Overall the diurnal curve of HOA tracks that of $\mathrm{CO}$ during the day, suggesting that there is little oxidation of HOA on a time scale of several hours. This observation is consistent with previous field studies which did not observe any appreciable aging of particle-phase alkanes over similar timescales (Schauer et al., 1996) and with recent laboratory studies which suggest that the time scale for such oxidation is on the order of one week (Molina et al., 2004). Note that small variations in the HOA/CO ratio may reflect differences in diurnal activity cycles of different sources which emit these species in different ratios, such as diesel and gasoline vehicles (Harley et al., 2005).

\subsubsection{Evolution of OOA during new particle growth}

We examine in this section a particle event on 12 September 2002 (Fig. 14) in which intense new particle formation was observed starting at 08:10 in the morning (Zhang et al., 2004). Meterological conditions in the beginning of this day resulted in low aerosol loadings that were favorable for new particle formation. The subsequent growth of these particles was observed as condensation of fresh secondary inorganic $\left(\mathrm{SO}_{4}^{2-}\right)$ and organic aerosol species that were formed from photochemical activity after 9:30 a.m. While an extensive discussion of the chemistry and microphysics of new particle growth for this event has been provided in a previous manuscript (Zhang et al., 2004), we revisit this event here because it offers a unique opportunity to probe and characterize the HOA and OOA content of freshly formed secondary organic aerosol species that are responsible for condensational growth of the new particles.

Figure 14 shows an overview of the time trends of various gas and aerosol species during this day. It is clear from the figure that the time series of HOA and $\mathrm{CO}$ track each other, staying flat from 10:00 a.m. to roughly 05:00 p.m., while the OOA concentration increased after $\sim 10: 00$ a.m., together with increase of $\mathrm{O}_{3}$. OOA continued to increase until 08:00 p.m. while $\mathrm{O}_{3}$ declined after $\sim$ 05:00 p.m., likely as $\mathrm{O}_{3}$ production decreased and was titrated by $\mathrm{NO}$ emitted from traffic, accentuated by reduced vertical mixing of the emitted NO in the late afternoon and evening.

Figures 14b-e display the image plots that illustrate the evolution of four aerosol parameters: condensational sink $\left(\mathrm{CS}\right.$, in units of $\mathrm{cm}^{-2}$ ) and the mass concentrations of $\mathrm{SO}_{4}^{2-}$, OOA, and HOA during 12 September 2002. CS is a measure of the available surface area for condensation (Pirjola 


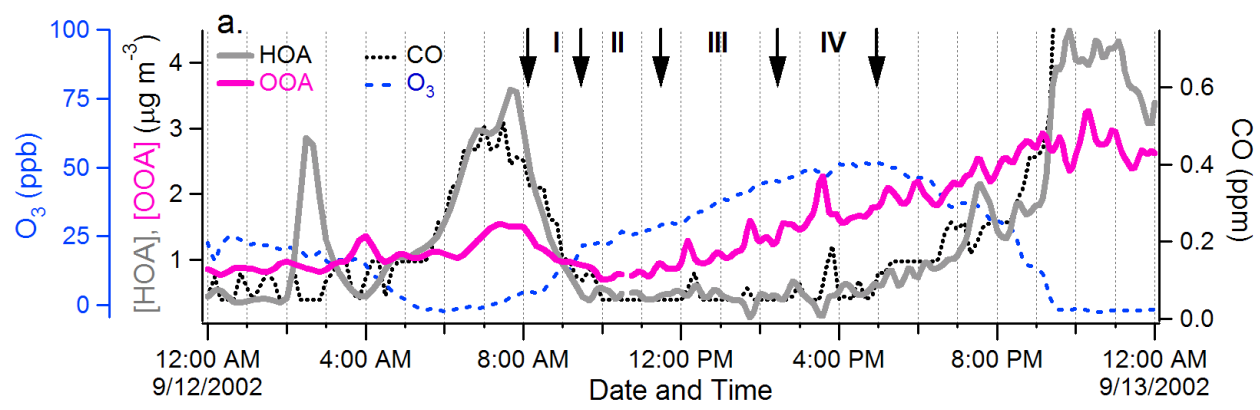

.... I: $8: 10-9: 30$

- II: 9:30 - 11:30

9/12/2002 Date and Time

III: $11: 30-14: 30$
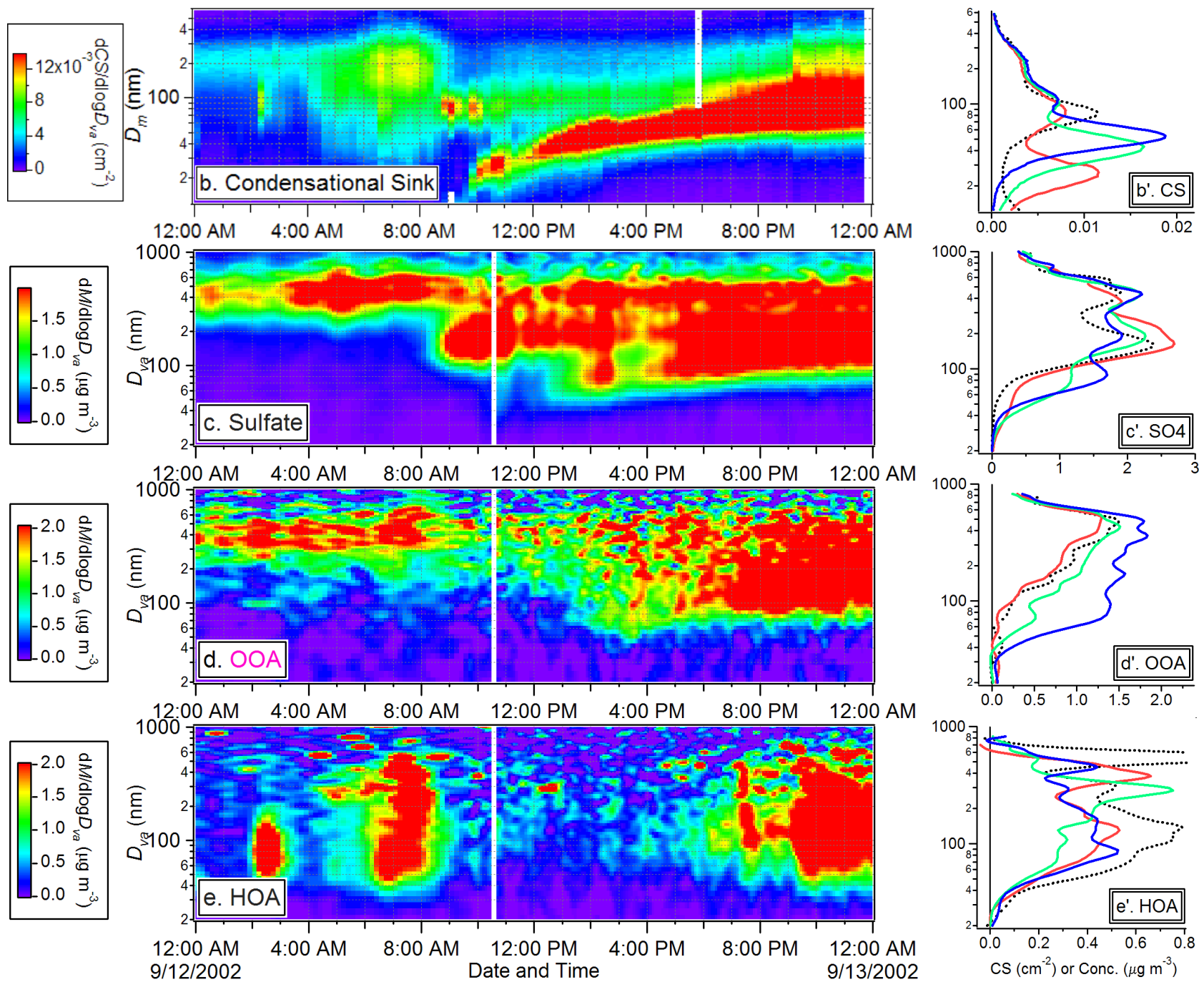

Fig. 14. (a) Time series of $\mathrm{HOA}, \mathrm{OOA}, \mathrm{CO}$, and $\mathrm{O}_{3}$, (b) evolution of the size distributions for condensational sink (CS) of vapor molecules with estimated molecular weight $=100 \mathrm{~g} / \mathrm{mol}$, and $(\mathbf{c}-\mathbf{e})$ mass concentrations of sulfate, OOA, and HOA during 12 September $2002-$ a day when an intense new particle formation event occurred at 08:10 a.m. The four stages (I-IV) of the nucleation and growth are marked on the plot (a). To the right of the corresponding image plot are the average size distributions of each parameter during these four stages (b'-e'). Missing data (white areas in plot and white areas in plots b-e) are due to either occasional instrumental malfunction or maintenance/calibration. 


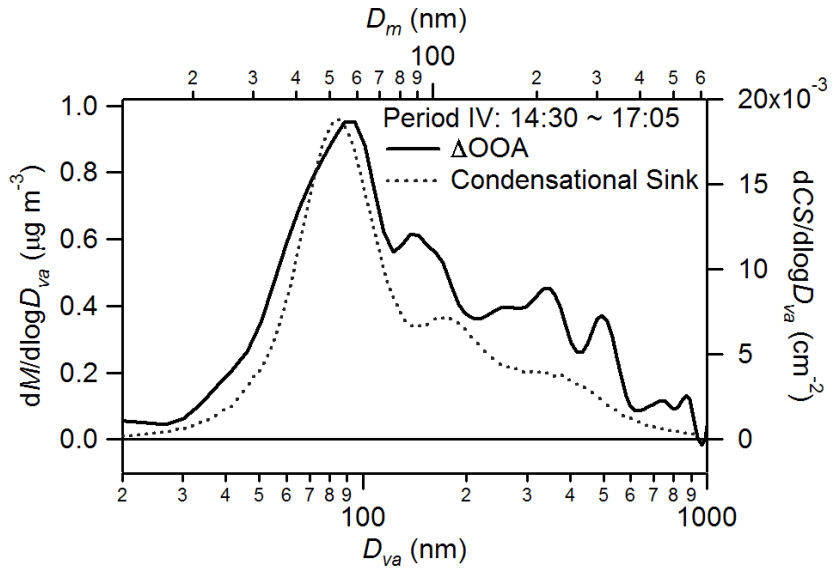

Fig. 15. Average size distribution of the condensational sink, and size distribution of the increase in OOA mass concentration ( $\triangle$ OOA) during 14:30-17:08 (period IV) on 12 September 2002. The condensational sink was estimated assuming that the average molecular weight of the condensable vapor molecules is $100 \mathrm{~g} / \mathrm{mol}$. A particle density of $1.5 \mathrm{~g} / \mathrm{cm}^{3}$ is assumed to relate $D_{m}$ to $D_{v a}$ $\left(D_{v a}=\rho \times D_{m}\right)$ (DeCarlo et al., 2004).

et al., 1999). It was calculated from the number distribution in the mobility diameter range of 3-680 nm as measured by SMPS assuming an average molecular weight for the condensing species of $100 \mathrm{~g} / \mathrm{mol}$. The image plots of HOA and OOA are relatively noisy because both are calculated from only one $\mathrm{m} / \mathrm{z}$ and therefore have lower signal-to-noise ratios. To the right of the image plots are the average size distributions of the corresponding parameters during four consecutive periods (I-IV) of this event (Figs. 14b'-14e'). Period I (08:10-09:30) corresponds to the initial stage of new particle formation when the nucleation mode particle number increased greatly; Periods II (09:30-11:30) and III (11:3014:30) represent the growth period when the number of nucleation mode particle number declined while the Aitken mode number increased; and Period IV (14:30-17:05) corresponds to a later period in the event when both the nucleation mode and the Aitken mode numbers were decreasing (Zhang et al., 2004). Note that the AMS can only detect particles that have grown into the Aitken mode ( $>33 \mathrm{~nm} D_{v a}$ ) (Zhang et al., 2004).

The evolution patterns of the size distributions of HOA and OOA are substantially different, with ultrafine HOA $(<100 \mathrm{~nm})$ decreasing sharply after 09:30 a.m. and ultrafine OOA increasing throughout the day. This OOA behavior is similar to that of sulfate, except that sulfate also exhibits an intermediate mode $\left(D_{v a}=\sim 100-250 \mathrm{~nm}\right)$ at the beginning of the event - during Periods I and II (Figs. 14c-d and 14c'-d'). As discussed in Zhang et al. (2004) the intermediate mode particles that suddenly appeared at around 08:00 a.m. on 12 September were composed of ammonium sulfate and likely were mixed in from the air mass aloft when the boundary layer grew in the morning. We speculate that these particles were the product of nucleation and growth in the previous day from a large $\mathrm{SO}_{2}$-containing air mass. However, although the intermediate mode contained little OOA during period I, an intermediate mode of OOA together with the ultrafine mode for this species gradually emerged after around noon or so (Figs. 14d and 14d'). By Period IV (14:30 17:05 EST) the size distributions of $\mathrm{OOA}$ and $\mathrm{SO}_{4}^{2-}$ are very similar and both show tri-modal characteristics (Figs. 14c, $14 c^{\prime}, 14 d$, and $\left.14 d^{\prime}\right)$, suggesting that the growth of OOA was due to condensation of secondary organics on all the available surface area.

Further evidence for this condensation mechanism is the fact that the growth patterns of OOA and sulfate (Figs. 14c and d) are consistent with the aerosol condensational sink distributions (Fig. 14b). This is seen more clearly in Fig. 15, which shows the size-dependent increase of the OOA concentration follows the average CS distribution during Period IV. In contrast, there is no obvious evidence of condensational growth of the HOA mode on this day (Figs. 14e and $\left.14 \mathrm{e}^{\prime}\right)$. These observations provide strong evidence that the increase in OOA during this event reflects condensation of freshly formed SOA, supporting the hypothesis that photochemically produced secondary organic aerosols played an important role in new particle growth during this event (Zhang et al., 2004).

Figure 16 compares the OOA mass spectrum observed during this new particle growth event with the OOA mass spectrum observed over the entire study period. These two spectra are very similar, suggesting that OOA in Pittsburgh (at least during this study) is primarily SOA. This hypothesis is consistent with the fact that 1) similar mass spectra suggest similar chemical compositions; 2) HOA oxidation appears to be negligible on the timescales of several hours (see Sect. 3.5.1); and 3) other oxygenated primary organic aerosols (including biomass burning and meat cooking OA) are unlikely to be present at significant concentration during this study (Pekney et al., 2005). The similarity between spectrum dominated by freshly formed SOA (with an apparent age of a few hours) and the average OOA during the study (with a likely average age of a few days) indicates that fresh SOA has a similar oxidation level (i.e. O:C ratio) as regional OOA in Pittsburgh. Since OOA appears to be highly oxygenated (see Sect. 3.3) this observation suggests that a large fraction of SOA in Pittsburgh is already highly oxygenated when first formed, rather than being produced by slow oxidation of a less-oxygenated fresh SOA.

Finally we can use the data in Fig. 14a to calculate the relative photochemical production rates of OOA and $\mathrm{O}_{3}$. Between 10:00 a.m. to 4:00 p.m. on 12 September 2002, $\mathrm{OOA}$ and $\mathrm{O}_{3}$ increase with a nearly constant growth rates of $\sim 0.19 \mu \mathrm{g} \mathrm{m}^{-3} \mathrm{~h}^{-1}$ for OOA and $5 \mathrm{ppb} \mathrm{h}^{-1}$ for $\mathrm{O}_{3}$, that yield an observed ratio $\sim 38 \mathrm{ng} \mathrm{m}^{-3} \mathrm{OOA} / \mathrm{ppb} \mathrm{O}_{3}$ (or equivalently $26 \mathrm{ppb} \mathrm{O}_{3} / \mu \mathrm{g} \mathrm{m}^{-3} \mathrm{OOA}$ ). As discussed above the concentrations of $\mathrm{OOA}$ and $\mathrm{O}_{3}$ do not correlate for the study as a 


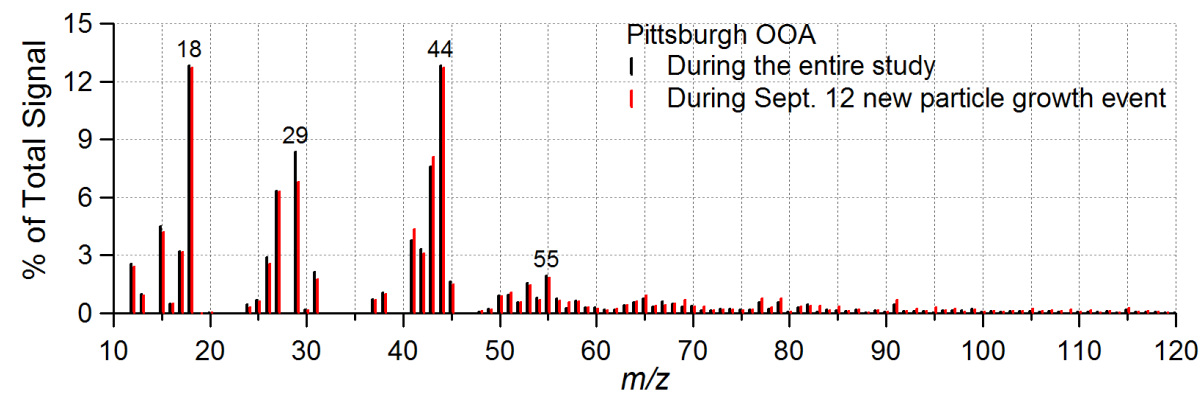

Fig. 16. Comparison of the OOA mass spectrum extracted from the entire study period vs. that during an intense new particle formation and growth period on 12 September 2002.

whole, likely due to the high background of OOA that buries its relatively small local production. However in the afternoon of 12 September 2002, because of the low background of OOA and intense UV light (Zhang et al., 2004), the increase of OOA due to photochemical production becomes more apparent and correlates with the increase of ozone. Although this ratio of observed SOA to $\mathrm{O}_{3}$ apparent production efficiencies is only characteristic of the air mass sampled that day, it is of great interest to compare it with other studies in the future.

\section{Conclusions}

This paper reports the mass concentrations, size distributions, and temporal variations of hydrocarbon-like and oxygenated organic aerosols in Pittsburgh during September 2002 and discusses the possible sources and processes of these two aerosol components. HOA and OOA together capture nearly $100 \%$ of the organic aerosol mass with HOA representing $34 \%$ of the total on average and OOA representing $66 \%$.

The time series of HOA correlates well with those of combustion source tracers, including $\mathrm{NO}_{\mathrm{x}}, \mathrm{CO}$, and $\mathrm{EC}$, and demonstrates a well-defined diurnal pattern that peaks during morning rush hours and decreases with the rise of the boundary layer. The size distribution of HOA shows a prominent ultrafine mode that on average accounts for $\sim 1 / 3$ rd of the HOA mass. These observations, together with the mass spectrum of HOA, which is dominated by ion series characteristic for long chain hydrocarbons, indicate a direct correspondence of HOA to primary OA from local emissions (likely from combustion processes).

The time series and size distribution of OOA are distinctly different from those of HOA, but show close similarity to those of $\mathrm{SO}_{4}^{2-}$ - a major secondary aerosol species in the Pittsburgh region. The diurnal profiles of both OOA and $\mathrm{SO}_{4}^{2-}$ are relatively flat and their size distributions are generally dominated by the accumulation mode. These observations, together with the fact that the mass spectrum of OOA highly resembles those of aged and oxidized OA, suggests the secondary and regional nature of Pittsburgh OOA. The direct correspondence of OOA to SOA is particularly evident during an intense new particle formation and growth event, when condensational growth of OOA was found to be mainly responsible for the increase of OOA mass. In addition, according to the observed $\mathrm{HOA} / \mathrm{CO}$ emission ratios and ambient $\mathrm{CO}$ levels, oxidation/aging of HOA appears to be very small on the time scale of several hours.

Based on the mass spectra of HOA and OOA and the likely elemental compositions of major $m / z$ 's, we estimated the carbon contents of HOA and OOA and their average OM:OC ratios, which are 1.2 and $2.2 \mu \mathrm{g} / \mu \mathrm{gC}$ for $\mathrm{HOA}$ and $\mathrm{OOA}$, respectively. The average OM:OC ratio for bulk organics is estimated at $1.8 \mu \mathrm{g} / \mu \mathrm{gC}$. This represents the first direct estimate of the OM:OC ratio from highly time-resolved chemical composition measurements. The total carbon concentrations $(=\mathrm{HOC}+\mathrm{OOC})$ thus estimated agree well with those measured by the Sunset Lab Carbon analyzer $\left(r^{2}=0.87\right.$; slope $=1.01 \pm 0.11)$. The carbon concentrations of HOA and OOA correlate well to those in POC and SOC estimated by the OC/EC tracer technique assuming POC-to-EC ratio=1, respectively. In addition, based on the comparisons of the fractional distribution of $\mathrm{HOC}$ and $\mathrm{OOC}$ to those of $\mathrm{POC}$ and SOC estimated from the EC/OC measurement applying different POC to EC ratios, it appears that the EC/OC tracer method can provide a useful estimation of POC and SOC, at least in Pittsburgh, as long as the correct POC/EC ratio is used.

\section{Appendix}

The AMS with a quadrupole mass spectrometer (Q-AMS) can only scan a subset of $m / z$ 's (typically $<20$ ) in the particle time-of-flight mode for a given study (Jimenez et al., 2003), from which the size distributions of bulk organic aerosols are estimated (Allan et al., 2003b). Depending on the selection of the organic $m / z$ 's scanned, the estimated size distribution of bulk organic aerosol may be biased to different degrees. Note that the new time-of-flight AMS (ToF-AMS) acquires the size distribution of each $m / z$ 's simultaneously 


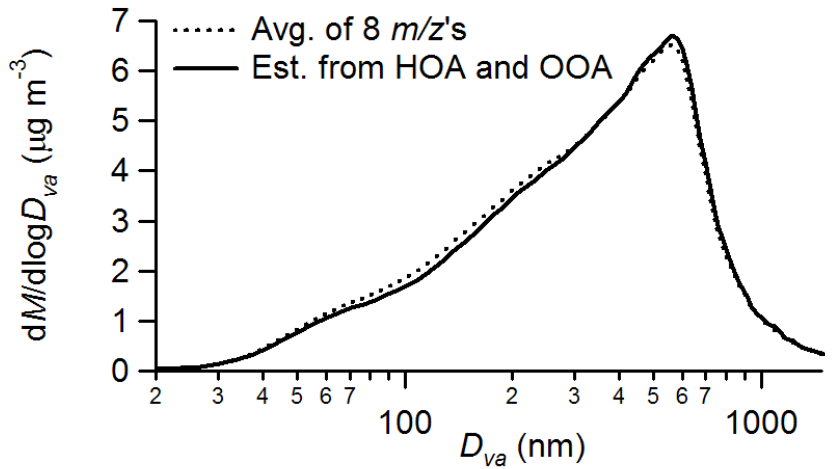

Fig. A1. Average size distribution of particulate organics estimated from the measured size distributions of 8 organic fragments $(\mathrm{m} / \mathrm{z}$ 's $27,43,44,55,57,67,91$, and 95) and that estimated from the size distributions of HOA and OOA.

and therefore can determine organic size distributions with little uncertainty (Drewnick et al., 2005). However, this instrument had not yet been developed at the time of this Pittsburgh study.

An alternative approach to estimate the size distribution of bulk organic aerosols is to add together those of HOA and OOA since these two components together account for more than $99 \%$ of the variance in the measured mass concentrations of organic aerosols in Pittsburgh (Zhang et al., 2005a). We therefore compare in Fig. A1 the average size distribution of organic aerosols for the entire study estimated based on the HOA and OOA size distributions to that based on the 8 organic $m / z$ 's scanned $(m / z$ 's $27,43,44,55,47,67,91$, 92) (Zhang et al., 2005b). These $8 \mathrm{~m} / z$ 's together account for $\sim 30 \%$, on average, of the total organic signal.

The overall agreement is good, suggesting that the $8 \mathrm{~m} / z$ 's selected for this study are representative and allow a reasonable reconstruction of the size distributions of organic aerosols in Pittsburgh. As a result, the organic size distributions reported in previous papers relevant to this study are reasonably accurate (Khlystov et al., 2005; Zhang et al., 2005b, 2004).

Acknowledgements. This research was supported by EPA STAR Grants R831080 and RD832161010, by NSF CAREER grant ATM 0449815, and by NASA Grant NNG04GA67G. Although this work has been partly funded by EPA, it has not been subjected to the Agency's review and therefore does not necessarily reflect the views of the Agency and no official endorsement should be inferred. The authors thank S. Pandis (CMU) for organizing and directing the PAQS campaign, C. Stanier (U. of Iowa) for particle number distribution data, B. Wittig (CUNY) for gas phase and meteorology data, R. Subramanian (UIUC), J. Cabada-Amaya (Tecnológico de Monterrey, Mexico), A. Robinson (CMU), A. Polidori and B. Turpin (Rutgers Univ.) for EC/OC data, and A. Aiken (CU) for high-resolution ToF-AMS data analysis. We also thank M. Hannigan (CU), A. Robinson, and N. Donahue (CMU) for helpful discussions.
Edited by: U. Pöschl

\section{References}

Alfarra, M. R.: Insights into Atmospheric Organic Aerosols Using an Aerosol Mass Spectrometer, Ph.D. Dissertation thesis, University of Manchester, Manchester, 2004.

Allan, J. D., Alfarra, M. R., Bower, K. N., Williams, P. I., Gallagher, M. W., Jimenez, J. L., McDonald, A. G., Nemitz, E., Canagaratna, M. R., Jayne, J. T., Coe, H., and Worsnop, D. R.: Quantitative sampling using an Aerodyne Aerosol Mass Spectrometer. Part 2: Measurements of fine particulate chemical composition in two UK Cities, J. Geophys. Res.-Atmospheres, 108(D3), 4091, doi:10.1029/2002JD002359, 2003a.

Allan, J. D., Jimenez, J. L., Williams, P. I., Alfarra, M. R., Bower, K. N., Jayne, J. T., Coe, H., and Worsnop, D. R.: Quantitative sampling using an Aerodyne Aerosol Mass Spectrometer. Part 1: Techniques of data interpretation and error analysis, J. Geophys. Res.-Atmospheres, 108(D3), 4090, doi:10.1029/2002JD002358, 2003b.

Allen, D. T., Palen, E. J., Haimov, M. I., Hering, S. V., and Young, J. R.: Fourier-Transform Infrared-Spectroscopy of aerosol collected in a Low-Pressure Impactor (LPI/FTIR) - Method development and field calibration, Aerosol Sci. Technol., 21(4), 325342, 1994.

Anderson, R. R., Martello, D. V., White, C. M., Crist, K. C., John, K., Modey, W. K., and Eatough, D. J.: The regional nature of $\mathrm{PM}_{2.5}$ episodes in the upper Ohio river valley, J. Air \& Waste Manage. Assoc., 54, 971-984, 2004.

Bates, T. S., Quinn, P. K., Coffman, D. J., Johnson, J. E., and Middlebrook, A. M.: Dominance of organic aerosols in the marine boundary Layer over the Gulf of Maine during NEAQS 2002 and their role in aerosol light scattering, J. Geophys. Res., 110, D18202, doi:10.1029/2005JD005797, 2005.

Blando, J. D., Porcja, R. J., Li, T. H., Bowman, D., Lioy, P. J., and Turpin, B. J.: Secondary formation and the Smoky Mountain organic aerosol: An examination of aerosol polarity and functional group composition during SEAVS, Environ. Sci. Technol., 32(5), 604-613, 1998.

Blando, J. D., Porcja, R. J., and Turpin, B. J.: Issues in the quantitation of functional groups by FTIR spectroscopic analysis of impactor-collected aerosol samples, Aerosol Sci. Technol., 35(5), 899-908, 2001.

Cabada, J. C., Pandis, S. N., and Robinson, A. L.: Sources of atmospheric carbonaceous particulate matter in Pittsburgh, Pennsylvania, J. Air \& Waste Manag. Assoc., 52(6), 732-741, 2002.

Cabada, J. C., Pandis, S. N., Subramanian, R., Robinson, A. L., Polidori, A., and Turpin, B.: Estimating the secondary organic aerosol contribution to $\mathrm{PM}_{2.5}$ using the $\mathrm{EC}$ tracer method, Aerosol Sci. Technol., 38(S1), 140-155, 2004a.

Cabada, J. C., Rees, S., Takahama, S., Khlystov, A., Pandis, S. N. Davidson, C. I., and Robinson, A. L.: Mass size distributions and size resolved chemical composition of fine particulate matter at the Pittsburgh Supersite, Atmos. Environ., 38(20), 3127-3141, 2004b.

Canagaratna, M. R., Jayne, J. T., Ghertner, D. A., Herndon, S., Shi, Q., Jimenez, J. L., Silva, P. J., Williams, P., Lanni, T., Drewnick, F., Demerjian, K. L., Kolb, C. E., and Worsnop, 
D. R.: Chase studies of particulate emissions from in-use New York city vehicles, Aerosol Sci. Technol., 38, 555-573, doi:10.1080/02786820490465504, 2004.

Castro, L. M., Pio, C. A., Harrison, R. M., and Smith, D. J. T.: Carbonaceous aerosol in urban and rural European atmospheres: estimation of secondary organic carbon concentrations, Atmos. Environ., 33(17), 2771-2781, 1999.

Chung, S. H. and Seinfeld, J. H.: Global distribution and climate forcing of carbonaceous aerosols, J. Geophys. Res., 107(D19), 4407, doi:10.1029/2001JD001397, 2002.

de Gouw, J. A., Middlebrook, A. M., Warneke, C., Goldan, P. D., Kuster, W. C., Roberts, J. M., Fehsenfeld, F. C., Worsnop, D. R., Canagaratna, M. R., Pszenny, A. A. P., Keene, W. C., Marchewka, M., Bertman, S. B., and Bates, T. S.: Budget of organic carbon in a polluted atmosphere: Results from the New England Air Quality Study in 2002, J. Geophys. Res.Atmospheres, 110(D16305), doi:10.1029/2004JD005623, 2005.

DeCarlo, P., Slowik, J. G., Worsnop, D. R., Davidovits, P., and Jimenez, J. L.: Particle morphology and density characterization by combined mobility and aerodynamic diameter measurements. Part 1: Theory, Aerosol Sci. Technol., 38, 1185-1205, 2004.

Decesari, S., Facchini, M. C., Fuzzi, S., McFiggans, G. B., Coe, H., and Bower, K. N.: The water-soluble organic component of size-segregated aerosol, cloud water and wet depositions from Jeju Island during ACE-Asia, Atmos. Environ., 39(2), 211-222, 2005.

Decesari, S., Facchini, M. C., Fuzzi, S., and Tagliavini, E.: Characterization of water-soluble organic compounds in atmospheric aerosol: A new approach, J. Geophys. Res.-Atmospheres, 105(D1), 1481-1489, 2000.

Decesari, S., Facchini, M. C., Matta, E., Mircea, M., Fuzzi, S., Chughtai, A. R., and Smith, D. M.: Water soluble organic compounds formed by oxidation of soot, Atmos. Environ., 36(11), 1827-1832, 2002.

Drewnick, F., Hings, S. S., DeCarlo, P. F., Jayne, J. T., Gonin, M., Fuhrer, K., Weimer, S., Jimenez, J. L., Demerjian, K. L., Borrmann, S., and Worsnop, D. R.: A new Time-of-Flight Aerosol Mass Spectrometer (ToF-AMS) - Instrument description and first field deployment, Aerosol Sci. Technol., 39, 637-658, 2005.

Drewnick, F., Schwab, J. J., Jayne, J. T., Canagaratna, M., Worsnop, D. R., and Demerjian, K. L.: Measurement of ambient aerosol composition during the PMTACS-NY 2001 using an Aerosol Mass Spectrometer. Part I: Mass concentrations, Aerosol Sci. Technol., 38(S1), 92-103, 2004a.

Drewnick, F., Schwab, J. J., Jayne, J. T., Canagaratna, M., Worsnop, D. R., and Demerjian, K. L.: Measurement of ambient aerosol composition during the PMTACS-NY 2001 using an Aerosol Mass Spectrometer. Part II: Chemically speciated mass distributions, Aerosol Sci. Technol., 38(S1), 104-117, 2004b.

Edney, E. O., Kleindienst, T. E., Conver, T. S., McIver, C. D., Corse, E. W., and Weathers, W. S.: Polar organic oxygenates in PM2.5 at a southeastern site in the United States, Atmos. Environ., 37(28), 3947-3965, 2003.

Facchini, M. C., Mircea, M., Fuzzi, S., and Charlson, R. J.: Cloud albedo enhancement by surface-active organic solutes in growing droplets, Nature, 401(6750), 257-259, 1999.

Finlayson-Pitts, B. J. and Pitts Jr., J. N.: Chemistry of the Upper and Lower Atmosphere: Theory, Experiments and Application, Academic Press, 2000.
Fuzzi, S., Decesari, S., Facchini, M. C., Matta, E., Mircea, M., and Tagliavini, E.: A simplified model of the water soluble organic component of atmospheric aerosols, Geophys. Res. Lett., 28(21), 4079-4082, 2001.

Gelencser, A.: Carbonaceous Aerosols, 350 pp., Dordrecht, The Netherlands, Springer, 2004.

Harley, R. A., Marr, L. C., Lehner, J. K., and Giddings, S. N.: Changes in motor vehicle emissions on diurnal to decadal time scales and effects on atmospheric composition, Environ. Sci. Technol., in press, 2005.

Haywood, J. and Boucher, O.: Estimates of the direct and indirect radiative forcing due to tropospheric aerosols: A review, Rev. Geophys., 38(4), 513-543, 2000.

IPCC, Climate Change 2001: The Scientific Basis, Contribution of Working Group I to the Third Assessment Report of the Intergovernmental Panel on Climate Change, edited by: Houghton, J. T., Ding, Y., Griggs, D. J., Noguer, M., van der Linden, P. J., Dai, X., Maskell, K., and Johnson, C. A., Cambridge Univ. Press, New York, 2001.

Jacobson, M. C., Hansson, H. C., Noone, K. J., and Charlson, R. J.: Organic atmospheric aerosols: Review and state of the science, Rev. Geophys., 38(2), 267-294, 2000.

Jayne, J. T., Leard, D. C., Zhang, X., Davidovits, P., Smith, K. A., Kolb, C. E., and Worsnop, D. R.: Development of an aerosol mass spectrometer for size and composition analysis of submicron particles, Aerosol Sci. Technol., 33, 49-70, 2000.

Jimenez, J. L.: Aerosol Mass Spectrometry Web Page (http://cires.colorado.edu/jimenez/ams.html), 2005.

Jimenez, J. L., Jayne, J. T., Shi, Q., Kolb, C. E., Worsnop, D. R., Yourshaw, I., Seinfeld, J. H., Flagan, R. C., Zhang, X., Smith, K. A., Morris, J. W., and Davidovits, P.: Ambient aerosol sampling with an Aerosol Mass Spectrometer, J. Geophys. Res., 108(D7), 8425, doi:10:1029/2001JD001213, 2003.

Johnston, M. V.: Sampling and analysis of individual particles by aerosol mass spectrometry, J. Mass Spectrometry, 35(5), 585595, 2000.

Kanakidou, M., Seinfeld, J. H., Pandis, S. N., Barnes, I., Dentener, F. J., Facchini, M. C., Dingenen, R. V., Ervens, B., Nenes, A., Nielsen, C. J., Swietlicki, E., Putaud, J. P., Balkanski, Y., Fuzzi, S., Horth, J., Moortgat, G. K., Winterhalter, R., Myhre, C. E. L., Tsigaridis, K., Vignati, E., Stephanou, E. G., and Wilson, J.: Organic aerosol and global climate modelling: a review, Atmos. Chem. Phys., 5, 1053-1123, 2005,

\section{SRef-ID: 1680-7324/acp/2005-5-1053.}

Khlystov, A., Zhang, Q., Jimenez, J., Stanier, C., Pandis, S., Canagaratna, M., Fine, P., Misra, C., and Sioutas, C.: In-situ concentration of semi-volatile aerosol using water-condensation technology, J. Aerosol Sci., 36, 866-880, 2005.

Kirchstetter, T., Harley, R., Kreisberg, N., Stolzenburg, M., and Hering, S.: On-road measurement of fine particle and nitrogen oxide emissions from light- and heavy-duty motor vehicles, Atmos. Environ., 33(18), 2955-2968, 1999.

Laurent, J. P. and Allen, D. T.: Size distributions of organic functional groups in ambient aerosol collected in Houston, Texas, Aerosol Sci. Technol., 38 Suppl., 82-91, 2004.

Li, Q. F. and Yu, J. Z.: Determination of total aerosol nitrogen by thermal evolution, Aerosol Sci. Technol., 38(4), 382-390, 2004.

Maria, S. F., Russell, L. M., Turpin, B. J., and Porcja, R. J.: FTIR measurements of functional groups and organic mass in aerosol 
samples over the Caribbean, Atmos. Environ., 36(33), 51855196, 2002.

McKeown, P. J., Johnston, M. V., and Murphy, D. M.: Online single-particle analysis by Laser Desorption Mass- Spectrometry, Analytical Chemistry, 63(18), 2069-2073, 1991.

Middlebrook, A., Murphy, D. M., Lee, S.-H., Thomson, D. S., Prather, K. A., Wenzel, R. J., Liu, D.-Y., Phares, D. J., Rhoads, K. P., Wexler, A. S., Johnston, M. V., Jimenez, J. L., Jayne, J. T., Worsnop, D. R., Yourshaw, I., Seinfeld, J. H., and Flagan, R. C.: An intercomparison of particle mass spectrometers during the 1999 Atlanta Supersite project, J. Geophys. Res.-Atmospheres, 108(D7), 8424, doi:10.1029/2001JD000660, 2003.

Middlebrook, A. M., Murphy, D. M., and Thomson, D. S.: Observations of organic material in individual marine particles at cape grim during the first aerosol characterization experiment (ACE 1), J. Geophys. Res.-Atmospheres, 103(D13), 16475-16483, 1998.

Millet, D. B., Donahue, N. M., Pandis, S. N., Polidori, A., Stanier, C. O., Turpin, B. J., and Goldstein, A. H.: Atmospheric VOC measurements during the Pittsburgh Air Quality Study: Results, interpretation, and quantification of primary and secondary contributions, J. Geophys. Res.-Atmospheres, 110, D07S07, doi:10.1029/2004JD004601, 2005.

Molina, M. J., Ivanov, A. V., Trakhtenberg, S., and Molina, L. T.: Atmospheric evolution of organic aerosol, Geophys. Res. Lett., 31, L22104, doi:10.1029/2004GL020910, 2004.

Murphy, D. M.: Atmospheric Science: Something in the Air, Science, 307(5717), 1888-1890, 2005.

Murphy, D. M., Thomson, D. S., and Mahoney, T. M. J.: In situ measurements of organics, meteoritic material, mercury, and other elements in aerosols at 5 to 19 kilometers, Science, 282(5394), 1664-1669, 1998.

NARSTO, Particulate Matter Science for Policy Makers: A NARSTO Assessment, EPRI 1007735, 2003.

Noble, C. A. and Prather, K. A.: Real-time single particle mass spectrometry: A historical review of a quarter century of the chemical analysis of aerosols, Mass Spectrometry Reviews, 19(4), 248-274, 2000.

Park, S. S., Harrison, D., Pancras, J. P., and Ondov, J. M.: Highly time-resolved organic and elemental carbon measurements at the Baltimore Supersite in 2002, J. Geophys. Res.-Atmospheres, 110, D07S06, doi:10.1029/2004JD004610, 2005.

Pekney, N., Davidson, C., Robinson, A., Zhou, L., Hopke, P., and Eatough, D. J.: Identification of major sources of PM2.5 in Pittsburgh using PMF and Unmix, Aerosol Sci. Technol., in press, 2005.

Pirjola, L., Kulmala, M., Wilck, M., Bischoff, A., Stratmann, F., and Otto, E.: Formation of sulphuric acid aerosols and cloud condensation nuclei: An expression for significant nucleation and model comparison, J. Aerosol Sci., 30(8), 1079-1094, 1999.

Robinson, A. L., Donahue, N. M., and Rogge, W. F.: Photochemical oxidation and changes in molecular composition of organic aerosol in the regional context, J. Geophys. Res., in press, 2005.

Rogge, W. F., Mazurek, M. A., Hildemann, L. M., Cass, G. R., and Simoneit, B. R. T.: Quantification of urban organic aerosols at a molecular level - Identification, abundance and seasonal variation, Atmos. Environ. Part A-General Topics, 27(8), 1309-1330, 1993.

Russell, L. M.: Aerosol organic-mass-to-organic-carbon ratio mea- surements, Environ. Sci. Technol., 37(13), 2982-2987, 2003.

Saxena, P. and Hildemann, L. M.: Water-soluble organics in atmospheric particles: A critical review of the literature and application of thermodynamics to identify candidate compounds, J. Atmos. Chem., 24(1), 57-109, 1996.

Saxena, P., Hildemann, L. M., McMurry, P. H., and Seinfeld, J. H.: Organics alter hygroscopic behavior of atmospheric particles, J. Geophys. Res.-Atmospheres, 100(D9), 18 755-18 770, 1995.

Schauer, J. J., Rogge, W. F., Hildemann, L. M., Mazurek, M. A., and Cass, G. R.: Source apportionment of airborne particulate matter using organic compounds as tracers, Atmos. Environ., 30(22), 3837-3855, 1996.

Seinfeld, J. H. and Pandis, S. N.: Atmospheric Chemistry and Physics: From Air Pollution to Climate Change, 1326 pp., Wiley, New York, 1998.

Seinfeld, J. H. and Pankow, J. F.: Organic atmospheric particulate material, Ann. Rev. Phys. Chem., 54, 121-140, 2003.

Sheehan, P. E. and Bowman, F. M.: Estimated effects of temperature on secondary organic aerosol concentrations, Environ. Sci. Technol., 35(11), 2129-2135, 2001.

Sheesley, R. J., Schauer, J. J., Hemming, J. D., Geis, S., and Barman, M. A.: Seasonal and spatial relationship of chemistry and toxicity in atmospheric particulate matter using aquatic bioassays, Environ. Sci. Technol., 39(4), 999-1010, 2005.

Suess, D. T. and Prather, K. A.: Mass spectrometry of aerosols, Chemical Reviews, 99(10), 3007, 1999.

Takegawa, N., Miyazaki, Y., Kondo, Y., Komazaki, Y., Miyakawa, T., Jimenez, J. L., Jayne, J. T., Worsnop, D. R., Allan, J. D., and Weber, R. J.: Characterization of an Aerodyne Aerosol Mass Spectrometer (AMS): Intercomparison with other aerosol Instruments, Aerosol Sci. Technol., 39(8), 760-770, 2005 b.

Tang, W., Raymond, T., Wittig, B., Davidson, C., Pandis, S., Robinson, A., and Crist, K.: Spatial variations of $\mathrm{PM}_{2.5}$ during the Pittsburgh Air Quality Study, Aerosol Sci. Technol., 38, Supplement 2, 80-90, 2004.

Turpin, B. J. and Huntzicker, J. J.: Secondary formation of organic aerosol in the Los Angeles basin: A descriptive analysis of organic and elemental carbon concentrations, Atmos. Environ., Part A. General Topics, 25(2), 207-215, 1991.

Turpin, B. J. and Huntzicker, J. J.: Identification of secondary organic aerosol episodes and quantitation of primary and secondary organic aerosol concentrations during SCAQS, Atmos. Environ., 29(23), 3527-3544, 1995.

Turpin, B. J. and Lim, H. J.: Species contributions to $\mathrm{PM}_{2.5}$ mass concentrations: Revisiting common assumptions for estimating organic mass, Aerosol Sci. Technol., 35(1), 602-610, 2001.

Turpin, B. J., Saxena, P., and Andrews, E.: Measuring and simulating particulate organics in the atmosphere: problems and prospects, Atmos. Environ., 34(18), 2983-3013, 2000.

Wittig, A. E., Anderson, N., Khlystov, A. Y., Pandis, S. N., Davidson, C., and Robinson, A. L.: Pittsburgh Air Quality Study overview and initial scientific findings, Atmos. Environ., 38, 3107-3125, 2004.

Yu, S., Dennis, R. L., Bhave, P. V., and Eder, B. K.: Primary and secondary organic aerosols over the United States: estimates on the basis of observed organic carbon (OC) and elemental carbon (EC), and air quality modeled primary OC/EC ratios, Atmos. Environ., 38(31), 5257-5268, 2004.

Zhang, Q., Alfarra, M. R., Worsnop, D. R., Allan, J. D., Coe, 
H., Canagaratna, M. R., and Jimenez, J. L.: Deconvolution and quantification of hydrocarbon-like and oxygenated organic aerosols based on aerosol mass spectrometry, Environ. Sci. Technol., 39(13), 4938-4952, doi:10.1021/es0485681, 2005a.

Zhang, Q. and Anastasio, C.: Chemistry of fog waters in California's Central Valley - Part 3: concentrations and speciation of organic and inorganic nitrogen, Atmos. Environ., 35(32), 56295643, 2001.

Zhang, Q. and Anastasio, C.: Free and combined amino compounds in atmospheric fine particles $\left(\mathrm{PM}_{2.5}\right)$ and fog waters from Northern California, Atmos. Environ., 37, 2247-2258, 2003.

Zhang, Q., Anastasio, C., and Jimenez-Cruz, M.: Watersoluble organic nitrogen in atmospheric fine particles $\left(\mathrm{PM}_{2.5}\right)$ from Northern California, J. Geophys. Res., 107(D11), 4112, doi:10.1029/2001JD000870, 2002a.
Zhang, Q., Canagaratna, M. C., Jayne, J. T., Worsnop, D. R., and Jimenez, J. L.: Time and size-resolved chemical composition of submicron particles in Pittsburgh - Implications for aerosol sources and processes, J. Geophys. Res., 110, D07S09, doi:10.1029/2004JD004649, 2005b.

Zhang, Q., Carroll, J. J., Dixon, A. J., and Anastasio, C.: Aircraft measurements of nitrogen and phosphorus in and around the Lake Tahoe Basin: Implications for possible sources of atmospheric pollutants to Lake Tahoe, Environ. Sci. Technol., 36, 4981-4989, 2002b.

Zhang, Q., Stanier, C. O., Canagaratna, M. R., Jayne, J. T., Worsnop, D. R., Pandis, S. N., and Jimenez, J. L.: Insights into the chemistry of new particle formation and growth events in Pittsburgh based on Aerosol Mass Spectrometry, Environ. Sci. Technol., 38(18), 4797-4809, 2004. 